\title{
Load model for designing flexible steel barriers for debris flow mitigation
}

\begin{tabular}{|r|l|}
\hline Journal: & Canadian Geotechnical Journal \\
\hline Manuscript ID & cgj-2016-0157.R5 \\
\hline Manuscript Type: & Note \\
\hline Date Submitted by the & 15 -Jun-2018 \\
\hline $\begin{array}{r}\text { Complete List of Authors: } \\
\text { Keyword: }\end{array}$ & $\begin{array}{l}\text { Wendeler, Corinna; Geobrugg AG, Technical Department } \\
\text { McArdell, Brian; Swiss Federal Institute WSL, Mass Movements } \\
\text { Bartelt, Perry; Swiss Federal Institute for Snow and Avalanche Research, }\end{array}$ \\
\hline $\begin{array}{r}\text { Is the invited manuscript for } \\
\text { consideration in a Special } \\
\text { Issue? : }\end{array}$ & Not applicable (regular submission) \\
\hline & \\
\hline
\end{tabular}

\section{SCHOLARONE Manuscripts}




\title{
Load model for designing flexible steel
}

\section{barriers for debris flow mitigation}

\author{
Corinna Wendeler, Axel Volkwein, Brian W. McArdell, and Perry \\ Bartelt
}

\begin{abstract}
Light-weight flexible steel net barriers catch coarse debris but let some of the fine material and water pass through the net. They are difficult to design to withstand the impact pressures of both boulder-laden granular and water-saturated debris flows. Using the results from laboratory and full-scale field tests, we have developed a debris flow load model for flexible barriers in torrent channels. The model a ccounts for the forces of initial impact as well as the filling process discretized stepwise over time (barriers in the field and laboratory fill continuously). Laboratory tests with fast debris flow front velocities revealed a run-up behaviour that was not observed in the field ("pile-up"). The load model divides the flow forces into a hydrostatic component and a dynamic part depending on a pressure coefficient, the flow velocity and the density of the flow. This dy namic part, which is more complex to quantify, accounts for the wide-ranging debris flow characteristics from watery and muddy debris floods to granular friction-dominated mass flows.
\end{abstract}

Key words: debris flows, load model, mitigation, protection, flexible barrier.

\section{Introduction}

An increasingly used measure to protect settlements and infrastructure from debris flow hazards is to install retention nets near mountain torrents (DeNatale, 1999; Wendeler, 2008; Canelli et al., 2012;

Corinna Wendeler, ${ }^{1}$ Axel Volkwein, ${ }^{2}$ and Brian W. McArdell. WSL Swiss Federal Institute for Forest, Snow and Landscape Research, 8903 Birmensdorf, Switzerland

Perry Bartelt. WSL Institute for Snow and Avalanche Research SLF, 7260 Davos-Dorf, Switzerland

${ }^{1}$ Present Address: Geobrugg AG, 8590 Romanshorn, Switzerland

${ }^{2}$ Corresponding author (e-mail: volkwein@wsl.ch). 
Bichler et al., 2012; Chan, 2012; Kwan et al., 2014; Albaba, 2015; Ashwood and Hungr, 2016). Net structures as for examples shown Figure 1a,b offer hazard engineers - in terms of erection costs a cost-efficient alternative to rigid structures, such as concrete or gabion check-dams, and therefore are of increasing interest to authorities. They stop and retain the solid material of debris flows to prevent large-scale damage downstream. Figure 1c shows a possible structural arrangement of the components of a flexible barrier. The steel net is spanned across the width of a riverbed using cables or steel wire ropes (both terms are used interchangeably by practitioners) as e.g. described in the standard DIN EN-12385 (2009). Additional so-called energy-absorbing elements provide a large deformation capacity that significantly increases the rope elongation under load. This enables the ropes to adjust their positions following the loads which in turn reduces the peak tensile forces in the ropes. In case a flexible barrier is designed to be overtopped by debris flows a series of steel elements (with chain-like connections) can be used to protect the top cable from abrasion.

The design of retention nets requires constructing light-weight (for efficient installation in steep terrain e.g. using helicopter), flexible steel structures that can withstand even very large static and dynamic loadings exerted by solid material consisting of debris, rocks and wood, travelling at speeds between 0.8 and $7 \mathrm{~m} / \mathrm{s}$ as measured by Badoux et al. (2009). This requires suitable dimensioning and design procedures. Special attention has to be paid to the durability of the steel structures regarding corrosion and the anchorages regarding river bank erosion. Further, net structures might suffer from impacting debris-flows requiring some maintenance over their lifetime.

Engineering guidelines defining debris flow impact loads exist, for examples, in the Swiss building insurance guidelines (Egli, 2005) or in other regulations such as CGS (2004) or NILIM (2007). But these guidelines do not fully consider the impact on mitigation measures; rather they provide engineers with methods to calculate debris flow impact pressures on buildings or obstacles. The impact force usually depends on the flow velocity squared (Salm et al., 1990). In Rickenmann (2001) a first step towards defining debris flow loads for flexible barriers is described. The design loads derived there were based on theoretical considerations and the suggested loads depending on the mass of the event and its momentum of inertia as well as velocity and the stopping time. It is an energy-conserving approach and limits the structural deformations of the system. Some experimental verification was presented to corroborate this design method. Hübl and Holzinger (2003) concentrated on laboratory experiments, without real-scale measurements for verification. They proposed scaling procedures for 
Fig. 1. a) Flexible debris flow barrier in Illgraben torrent (Switzerland; b) Flexible debris flow barrier in Illgraben torrent (Switzerland after debris flow event from 18 May 2006; c) possible arrangement of structural components of a flexible debris flow barrier (Volkwein, 2014) and its rough dimensions in Illgraben torrent.

a)

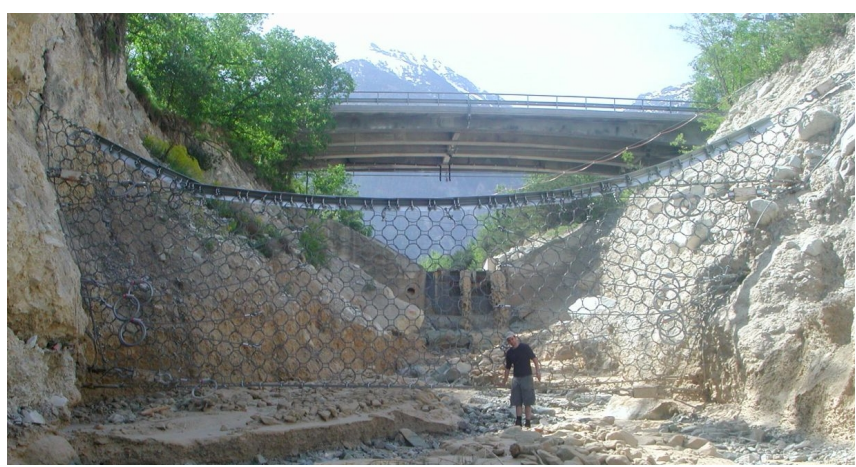

b)
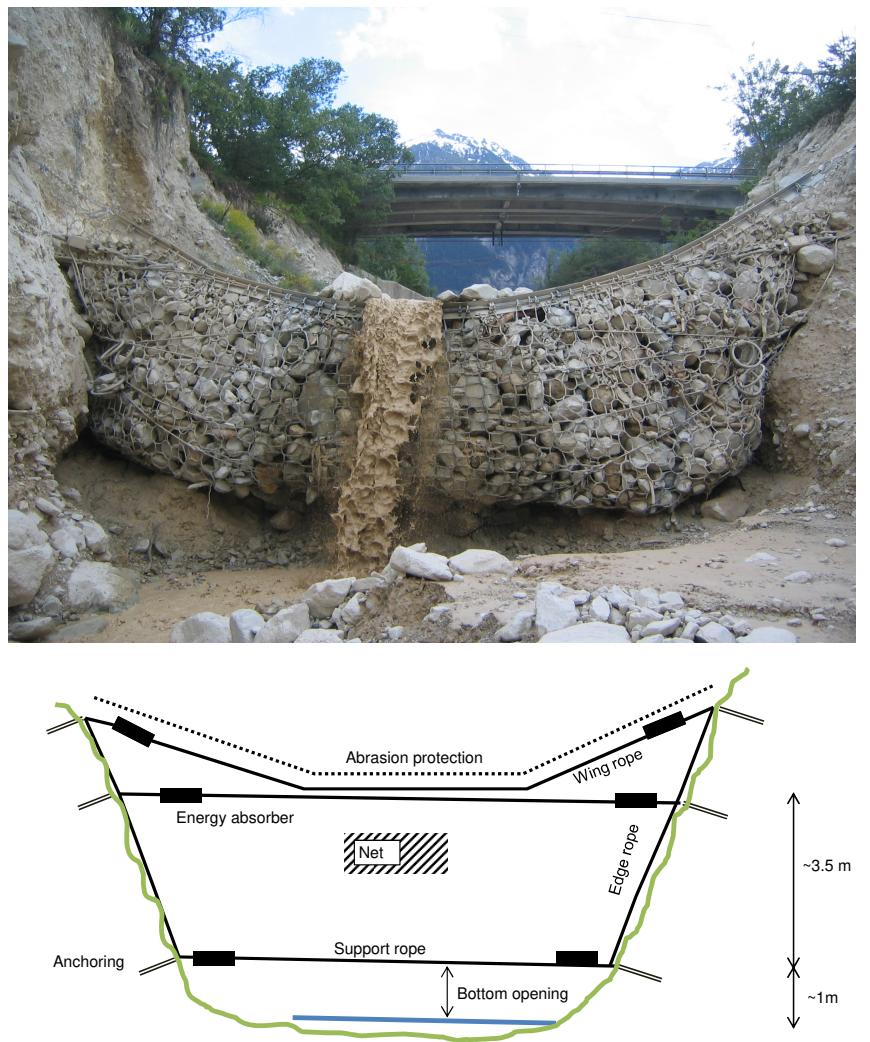

c)

$\sim 15 \mathrm{~m}$

barriers in the field. Brighenti et al. (2013) also propose a load model on flexible barriers based on the findings of Canelli et al. (2012). This load model has also been used for numerical simulations and was evaluated in large scale experiments (Brighenti et al., 2015). Recently, also Choi et al. (2015) described results from small scale chute experiments and the run-up mechanism of debris flow on rigid obstacles. 
Further experimentation on impact loads due to debris impacts in scale tests has been reported. Cui et al. (1999) measured the pressure distribution over the height of an obstacle. Zanuttigh and Lamberti (2004) described the forming of the typical debris flow surges. Hübl et al. (2009) compare different loading coefficients based on mid-scale tests in the field. Kwan et al. (2015) did a comprehensive analysis of the expected loads based on numerical simulations, field observations and laboratory tests. Further experimentation also using a centrifuge was reported in Ng et al. (2016a); Ng et al. (2016b). Ashwood and Hungr (2016) also used laboratory experiments to develop and to evaluate a load model. Thorough laboratory testing series with impact of small-scale debris flows onto rigid and flexible barriers recently were reported in Chanut et al. (2010); Choi et al. $(2015,2017)$ and Faug et al. (2012). Koo et al. (2016) compare their small-scale model with a field event. In Faug (2015) numerous test data are merged into a common scaling law. Ng et al. (2017) evaluate the interaction of dual barrier systems with a serial arrangement in the flow.

In this contribution, we propose a load model based on the doctoral dissertation Wendeler (2008) (in German; see Wendeler (2016) for English translation) that allows engineers to define the debris flow loadings on retaining net structures. The design procedure is still under international evaluation. There is not yet enough experience on the performance of the barriers that have been designed according to the design procedure: even if a barrier successfully retains a natural debris flow it only means that the design procedure is on the safe side. The remaining reserves of a system are not known yet. Nevertheless, the design procedure already has explicitly been implemented e.g. in Kwan and Cheung (2012). The procedure is mainly based on the full-scale testing of an instrumented net structure under the impact of real-scale debris flows supported by additional laboratory-scale physical model experiments (Wendeler, 2008; Wendeler and Volkwein, 2015). However, even if data from field events is available where natural debris flows impacted net barriers, the results and conclusions drawn have to be handled with care. A single event is unique and the properties of debris flows as well as the local channel conditions are variable (Iverson, 2015). In addition, in-situ measurements may not necessarily be representative for the entire flow or they may be difficult to interpret. Given all these uncontrollable factors, we consider it as important to base the load model not only on field measurements. Moreover, any information that improves the understanding of debris flow impact loads and the interaction with a barrier helps to formulate a reliable load model. Therefore, we address several issues related to the development of the load model, including physical modelling in a laboratory chute with appropriate 
dimensional analysis, full-scale barrier installation and measurement during a natural debris flow including measurements. Afterwards we describe the new load model as well as an analytical approach to calculate the loads acting in the barrier components. Finally, we compare the load model with other approaches.

We first discuss the physical modelling part of this work, which is based on earlier research performed by Weber (2004), where most of the detailed information about the laboratory chute and measurement facilities is explained. This facility allows to determine the impact forces on different kinds of barrier for small-scale debris flows with diverse materials, volumes, water contents and flow velocities.

Field scale measurements of debris flow impacts and the resultant structural forces are rare and require a robust experimental infrastructure to withstand the rough conditions of natural torrent channels. More importantly, the full-scale instrumentation is ideally placed in channels where several debris flows per year are possible. To test the barrier components in full-scale field tests, a site with several natural debris flows per year - the Illgraben-was chosen. The Illgraben is situated in south-west Switzerland, in the Canton of Valais. A debris flow research station has been in operation since 2001 (Hürlimann et al., 2003; McArdell et al., 2007). Here, an instrumented test site for flexible barriers was operated from 2005 to 2008. The measurements allowed us to understand and to develop but also to verify the load model. Both field tests and physical modelling help to describe the physics of a debris flows interacting with a flexible, light-weight structure.

\section{Physical modelling of net barriers}

The laboratory experiments (Wendeler, 2008, 2016; Wendeler and Volkwein, 2015) as sketched in Figure 2 were performed with a $3.7 \mathrm{~m}$ long and $0.3 \mathrm{~m}$ wide chute for which the inclination was varied between $14-26^{\circ}$. The goal of the small-scale experiments was to check whether results of the laboratory tests can be transferred to full scale barriers based on a dimensionless analysis. Further, the laboratory tests help to study the influence of different test configurations such as debris flow volume, debris composition, chute inclination, barrier deformability, or mesh sizes. The influence of different mesh sizes according to (Wendeler and Volkwein, 2015) is illustrated in Figure 3.

Mixtures of natural sediments and water with total volumes of $0.05-0.15 \mathrm{~m}^{3}$ were used, similar to experiments described by Rickenmann et al. (2003) in the same channel. Sediment mixtures from the rivers Illgraben, Merdenson (Canton Valais, Switzerland), Millibach, and Trachtbach (Canton Bern, 
Fig. 2. Physical modelling experiments (Wendeler and Volkwein, 2015): cross section of experimental set-up with head box for release, acceleration and measurement sections. The sledge at the lower end of the chute carries the barriers.

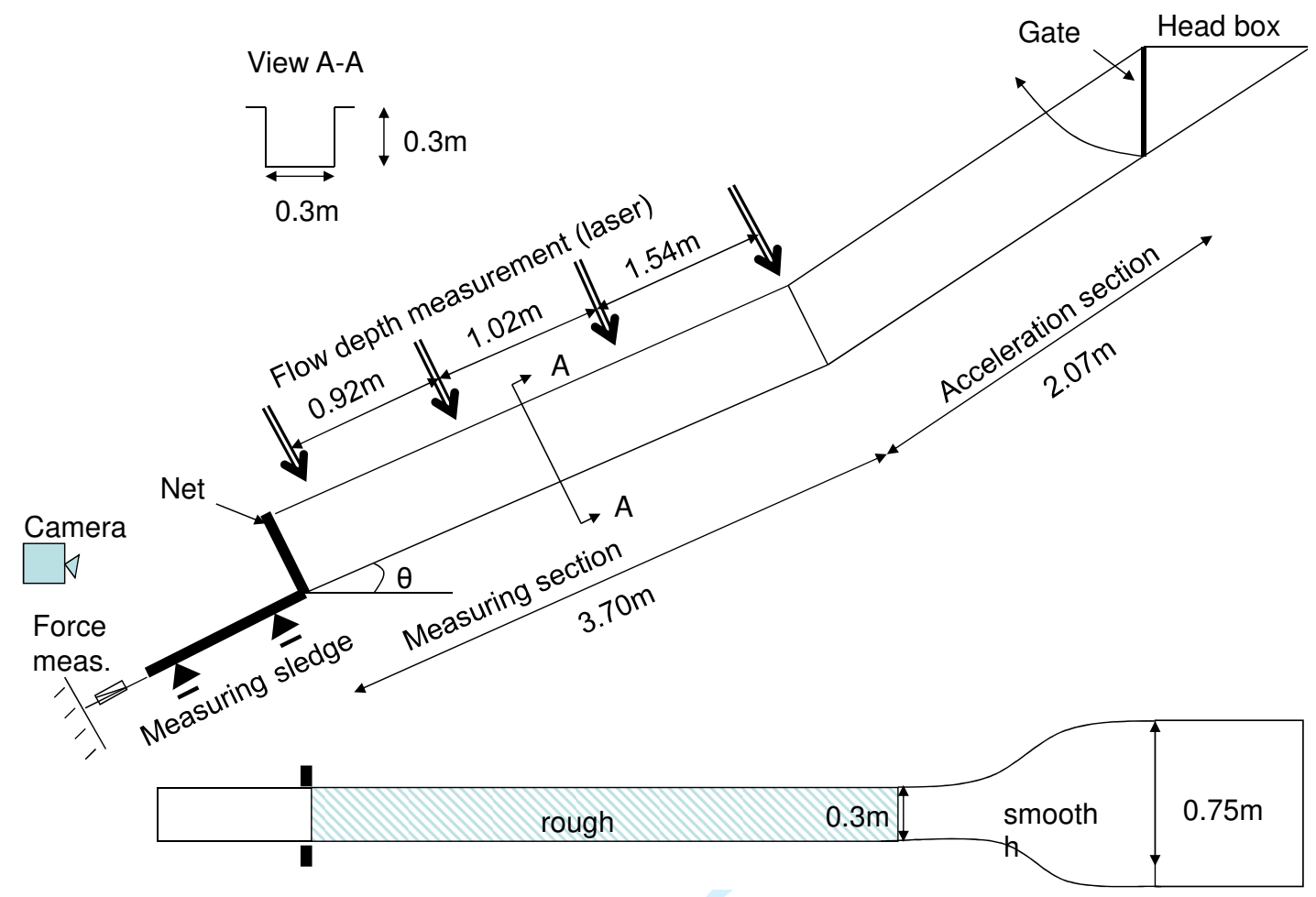

Fig. 3. Small-scale net barriers with different mesh sizes after laboratory tests (Wendeler and Volkwein, 2015): (a) $3 \mathrm{~cm}$ mesh size kept nearly the same amount of material as (b) $4 \mathrm{~cm}$ mesh size. (c) The retained volume with the $6 \mathrm{~cm}$ mesh size is only two thirds compared to the two other mesh sizes.
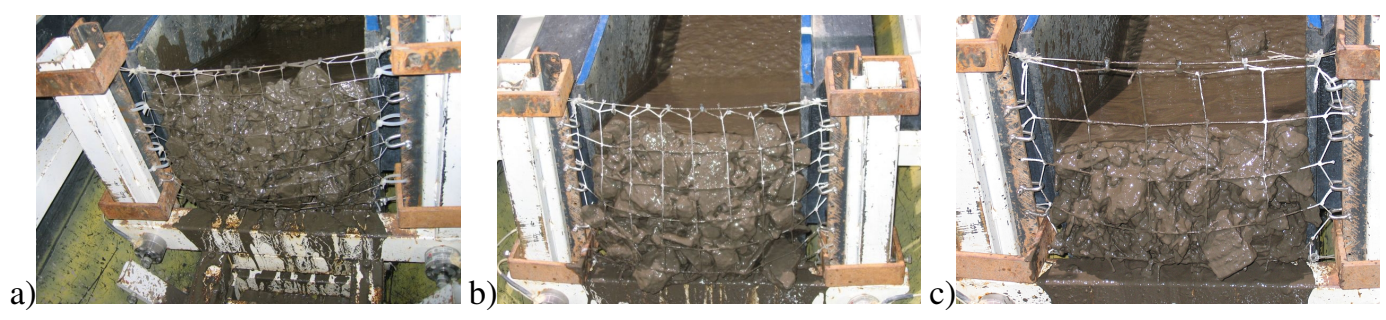

Switzerland) were used. In all cases the sediments were processed to eliminate particles larger than $3 \mathrm{~cm}$. Mixtures were reconstituted with water to produce mixtures which would flow rapidly in the laboratory channel (Wendeler, 2008, 2016). We took special care to obtain a certain degree of repeatability of the laboratory tests. A remaining degree of scatter might be expected due to natural variability of the natural sediment mixtures and small variations of water content. The latter has been measured after the tests by drying and weighing. The segregation of the mixture in the release box has been avoided 
by a maximum possible reduction of the time between filling and release.

The flow behaviour depended on the flow material, release volume and slope angle. When the masses were released from the head box by way of a gate, which was rapidly rotated up and away from the sediment in the head box, the flow depths rapidly decreased along the chute from $30 \mathrm{~cm}$ to less than $10 \mathrm{~cm}$ (Fig. 5a) when the masses impacted the small-scale barriers. Some of the flows developed roll waves and impacted the barriers in multiple surges. Impact velocities of the first surge were typically between $1 \mathrm{~m} / \mathrm{s}$ and $4 \mathrm{~m} / \mathrm{s}$ (Fig. 5b). Generally, by the time the flow front reached the barrier, the front velocity was either constant or slightly decreasing (Fig. 5b) indicating steady or decelerating flows, respectively. This also indicates considerable internal shearing induced by the basal roughness.

At the lower end of the chute a steel frame, called herein a sledge, has been installed to facilitate accurate measurement of impact forces. The sledge is oriented parallel to the channel inclination. It is supported orthogonal to the channel floor through four rubber cylinders that allow minimal movements of the sledge in flow direction (Fig. 4d). At the lower up-slope end of the sledge two load cells measure the total load over time in flow direction acting on the sledge respectively the barrier structure (Fig. 4e). Additional screws through the centres of the load cells permit a balancing of load activation prior to the experiments.Uplifting of the sledge is prevented through additional screws (Fig. 4c).

At the up-slope end of the sledge a U-shaped steel frame is visible in Figure 4a. Both upright sections of the "U" have a slit directed to the inside of the "U" where either a rigid plate (Fig. 4b) or small T-profiles (Fig. 4c) can be installed. The latter are drilled along the web so that nets can be attached as shown in Figure 3. The flexible net structure has been achieved by the use of simple plastic nets that commonly are available for home gardening. Once installed, the net was mounted loosely and additional strains due to acting loads were negligible. During our experiments we did not observe failure of a net. Due to the different structure of the nets in the laboratory compared to the nets used in the field a scaling of the maximum loads was not possible and we did not check for their maximum load bearing capacity. In contrast to the field installations the laboratory tests had no energy dissipaters installed between the net and the load cells. The sledge has a total weight of about $27 \mathrm{~kg}$. Due to the fixed support in flow direction through the load cells we estimate inertial effects during the debris impact with a weight of $90-270 \mathrm{~kg}$ as negligible.

Apart from the laboratory tests using flexible mesh barriers we also conducted tests with rigid barriers, i.e. plates in the channel with same dimensions but no openings. Table 1 and Figure 6 show 
Fig. 4. Sledge carrying the impacted barriers: (a) sledge without barrier; (b) rigid barrier installed (uplifting prevented using additional wedges); (c) preparation for installation of flexible net with visible lower and upper support ropes (uplifting prevented using four steel clamps); (d) view into flow channel from down-slope with detail of support orthogonal to the channel slope; (e) detail of fixed support and load measurement in flow direction parallel to the channel.
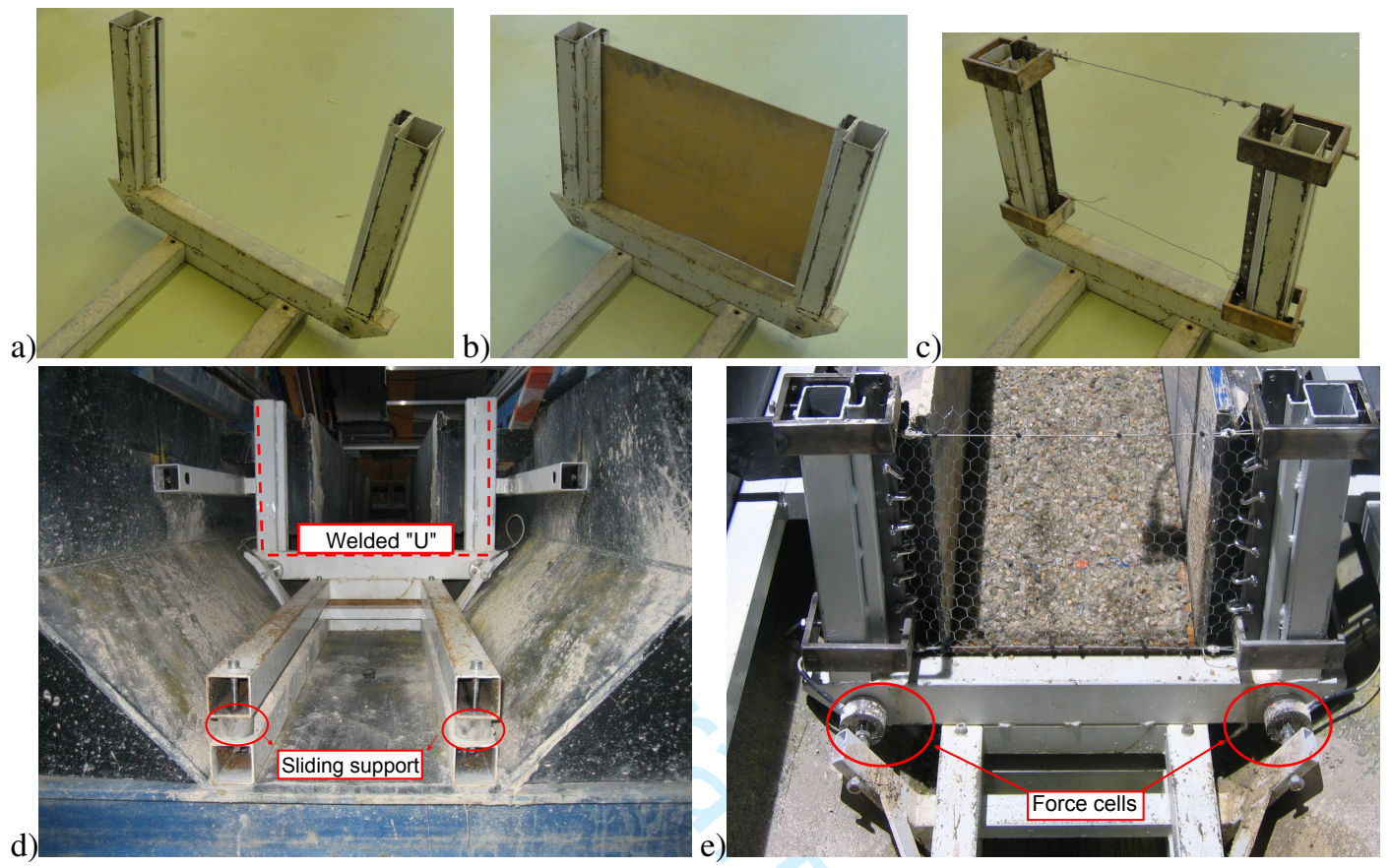

details for six similar tests, two with rigid plates and four with different nets. The laboratory debris flows are similar regarding debris flow mixture, debris flow volume and channel inclination. Table 1 gives the main results, i.e. impact speed, flow depth at impact location, and the maximum total retention forces during impact and after the test, Figure 6 shows the total loads in flow direction over time. A video compilation of tests 20, 23 and 27 showing the impacts on Plexiglas, a plastic net and a steel net can be found on Wendeler (2006).

The horizontal axis of the diagram in Figure 6 gives the time with respect to the release of the debris flows. The diagram therefore indicates that all debris flows arrive at about the same time at the barriers and, hence, are comparable in terms of impact velocity and flow depth. After impact two main characteristics can be seen: for the flexible barriers the maximum impact load and the final static load are larger than for the rigid plates.

This, on a first view, inaccurate result is interpreted in two ways. First, it can be explained because the different barriers cause different physical processes which are known as "run-up" and "pile-up" as 
Fig. 5. (a) Flow depths and (b) front velocities of laboratory tests with material from different riverbeds (Illgraben, Trachtbach, Merdenson \& Alpbach) and different chute inclinations $\left(14-26^{\circ}\right)$ performed using different volumes $50,100 \& 150$ litres. Flow depths were measured with a precision of $0.1 \mathrm{~mm}$. Flow velocities were determined by averaging over the distance between two flow depth measurements resulting in a precision of $0.2 \mathrm{~m} / \mathrm{s}$. The zero flow depth in (a) does not reflect to a measurement but is related to splatter on the distance laser sensor, the corresponding flow velocity has been derived from video records.

a)

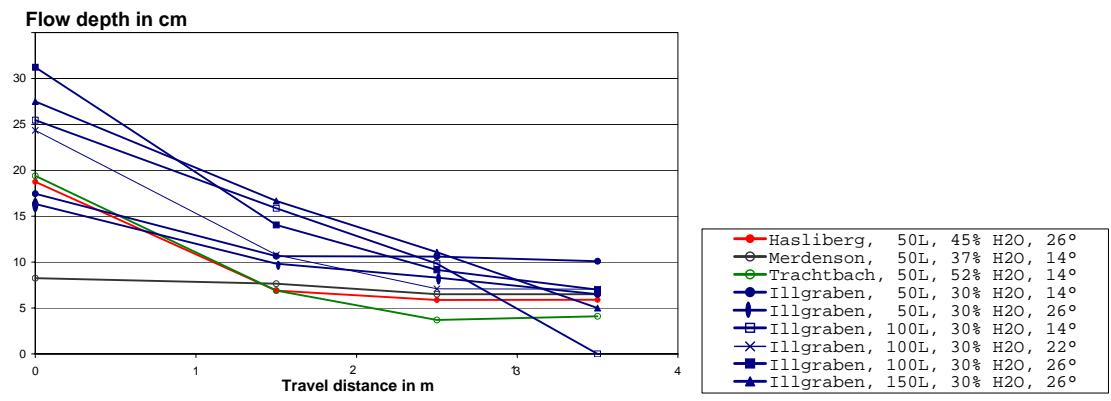

Front velocity in $\mathrm{m} / \mathrm{s}$

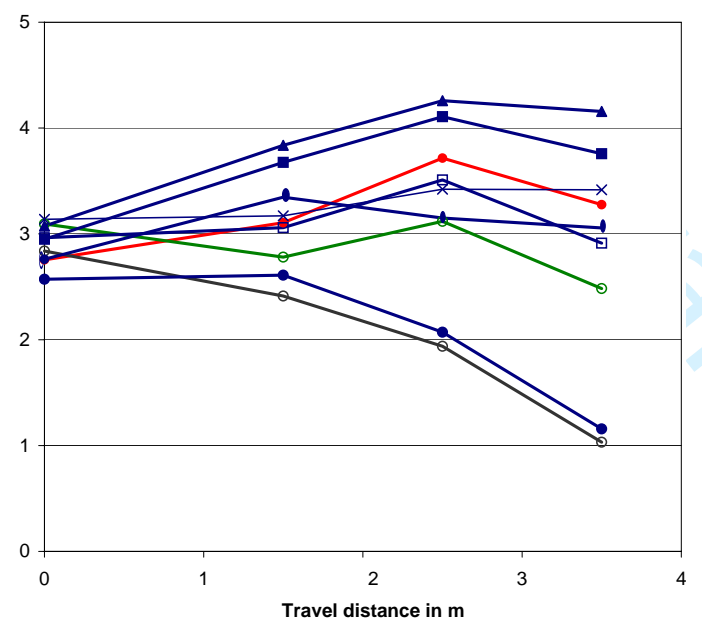

b)

ravel distance in $\mathrm{m}$

already distinguished by Song et al. (2017): Based on high-speed video records, we observed a "runup" process for the impact on the rigid plate: the debris flow material impacting the barrier first is being stopped and forms a so-called "dead zone" (Chanut et al., 2010; Song et al., 2017; Koo et al., 2017; Song et al., 2018). Due to the relatively large flow velocities of the debris mixtures in the laboratory tests the following material is not being stopped anymore but deviated up into the air orthogonal to the channel bed. Absorption of the mixture's kinetic energy then happens by conversion into potential energy. After reaching the highest point (kinetic energy $=0 J$ ), the mud is accelerated downward impacting the channel bed downstream of the barrier. If - for the rigid plates - the dead zone increases as the barrier fills up the dead zone material is deposited mainly in front of the barrier/sledge on the 
Table 1. Comparison of similar debris flows impacting a rigid plate and a flexible barrier in laboratory with a test setup as described in Wendeler and Volkwein (2015).

\begin{tabular}{|c|c|c|c|c|c|c|c|}
\hline Test no. & & 15 & 20 & 16 & 17 & 23 & 27 \\
\hline Barrier type & & $\begin{array}{l}\text { wooden } \\
\text { plate }\end{array}$ & Plexiglas & $\begin{array}{c}\text { steel net } \\
\text { (Jakob) }\end{array}$ & $\begin{array}{c}\text { chicken } \\
\text { wire }\end{array}$ & $\begin{array}{c}\text { plastic } \\
\text { mesh }\end{array}$ & $\begin{array}{l}\text { steel net } \\
\text { (Tecco) }\end{array}$ \\
\hline Mesh width & $\mathrm{mm}$ & 0 & 0 & 20 & 16 & 20 & 30 \\
\hline Slope inclination & $\%$ & 50 & 50 & 50 & 50 & 50 & 50 \\
\hline Debris flow volume & $m^{3}$ & 0.05 & 0.05 & 0.05 & 0.05 & 0.05 & 0.05 \\
\hline Water content & $k g$ & 12.2 & 12.1 & 10.7 & 10.7 & 10.5 & 11.5 \\
\hline Granular content & $k g$ & 92.8 & 95.6 & 97.0 & 97.0 & 97.22 & 96.2 \\
\hline Maximum grain size & $m m$ & 30 & 30 & 30 & 30 & 30 & 30 \\
\hline Impact velocity & $\mathrm{m} / \mathrm{s}$ & 2.74 & 3.53 & 3.02 & 3.08 & 3.94 & 3.03 \\
\hline Flow depth & $\mathrm{mm}$ & 93 & 43 & 97 & 109 & 66 & 67 \\
\hline Maximum impact force & $N$ & 220 & 200 & 440 & 330 & 390 & 405 \\
\hline Final static load & $N$ & 175 & 155 & 340 & 280 & 335 & 300 \\
\hline
\end{tabular}

Fig. 6. Total load in flow direction over time of $0.05 \mathrm{~m}^{3}$ debris flows (see Table 1 for details) impacting different barriers in the laboratory. The time after release indicates that all debris flows arrive at the barrier at about the same time, i.e. had about the same travel and impact velocities. The load curves for the rigid plates made from plexiglass and wood show a different load behaviour over time compared to all net structures: the maximum dynamic load is much closer in magnutude in relation to the final static load. The final static load is higher for the net structures compared to the plates.

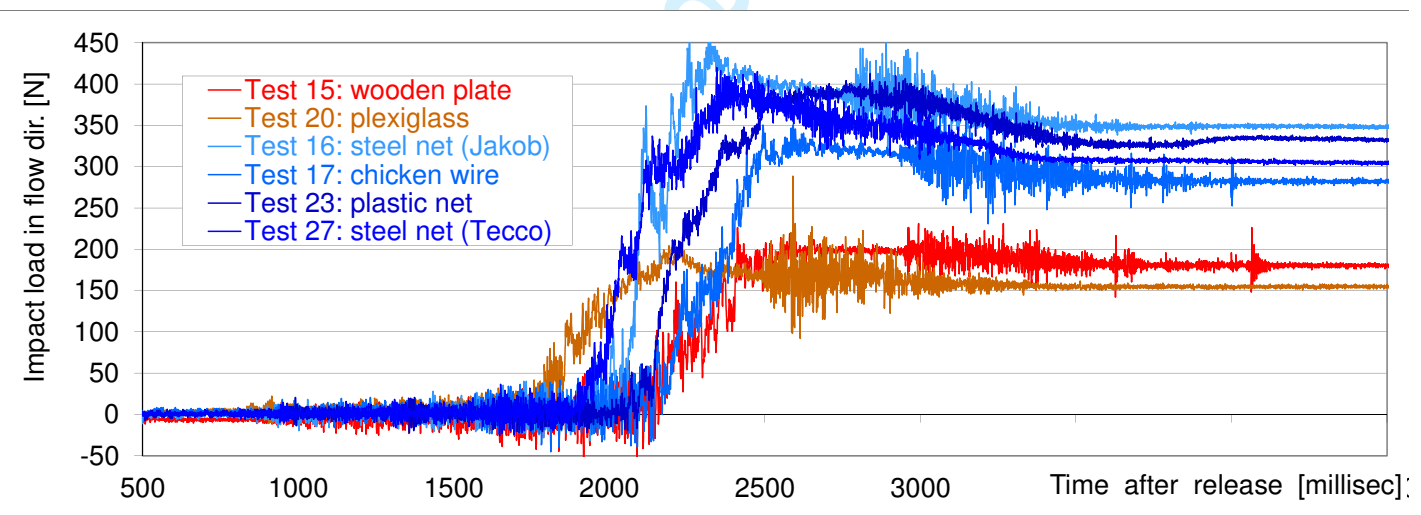

channel's floor. So, the impact load in flow direction of the oncoming material is transferred to the chute floor which reduces the loads measured at the barrier/sledge.

If the debris mixture impacts a flexible barrier, the oncoming debris is caught by the net, partly drained and the speed is retarded. We interpret this that the more kinetic energy is absorbed by the barrier compared to the tests with a rigid plate and higher maximum loads in flow direction are measured. Song et al. (2018) explain above behaviour that the large deformation of flexible barrier allows the debris to dissipate more internal energy and the deformed barrier also able to redirect the flow due 
Fig. 7. Cross-section through retained material after laboratory tests.

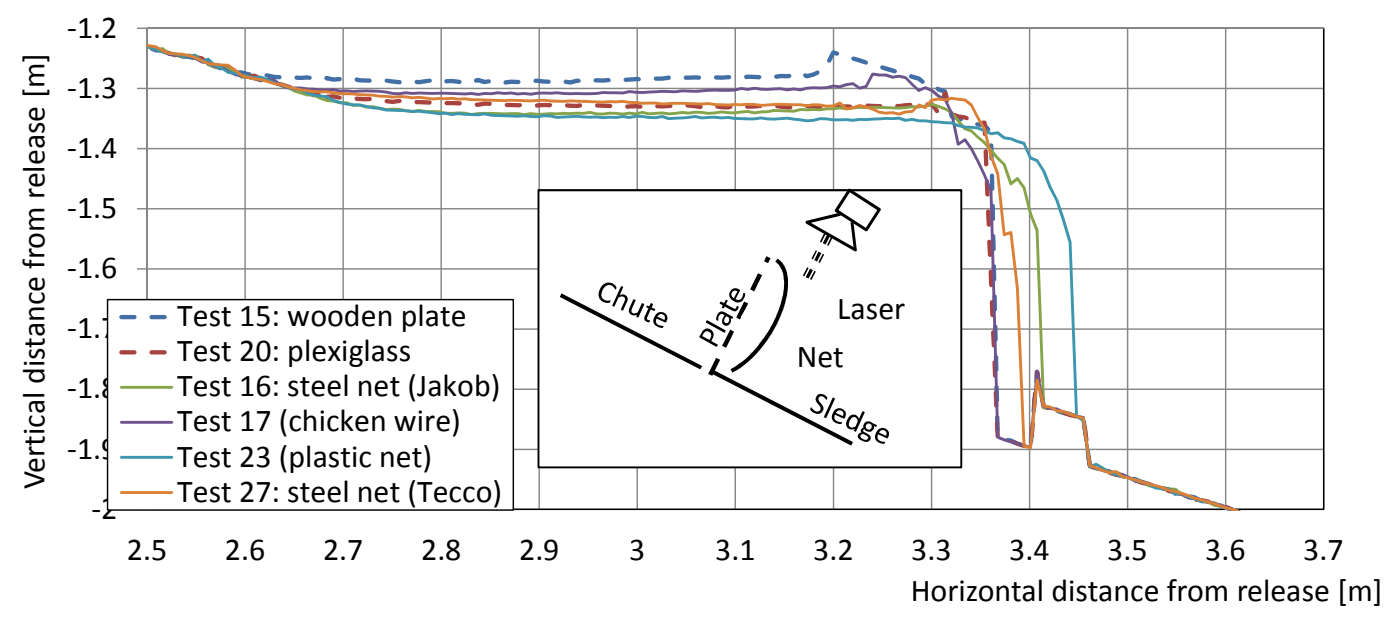

to dead zone formation of granular material. Further, the curved net shape favourizes the formation of a reflected wave as illustrated in Figure 9b or also described by Choi et al. (2017).

The higher static load in fully filled state of net barriers compared to rigid ones is interpreted as follows. The barriers tested are situated at the up-lope end of the sledge. After all tests, the main part of the debris rests on the slope before the sledge and does not load the barrier or sledge, respectively. In Figure 7 the cross-sections of the retained material after the tests are shown obtained from a post-event laser scan along the chute. Comparing the filled rigid barrier with a flexible one we observe that the flexible one extends over the sledge and therefore more material contributes to the static load. The rigid barrier retains all debris up-slope of the sledge.

\subsection{Dimensionless analysis}

To determine the applicability of the model results to the full-scale problem and to better understand the physical processes, we performed a dimensional analysis. We identified nine dimensionless numbers (Wendeler and Volkwein, 2015) and found five of the nine to be significant for our investigations because they specifically describe the barrier-debris interaction process. The five significant dimensionless quantities are (Wendeler, 2008):

$$
\Pi_{1}=\frac{P_{\text {total }}}{\rho u^{2}}, \quad \Pi_{2}=\frac{g h_{f}}{u^{2}}=\frac{1}{F r^{2}}, \quad \Pi_{3}=\frac{t_{i m p} u}{h_{b}}, \quad \Pi_{4}=\frac{V}{h_{f}^{2} b} \quad \text { and } \quad \Pi_{5}=\frac{h_{b}}{h_{f}}
$$

with $u[\mathrm{~m} / \mathrm{s}]$ being the flow velocity, $\rho\left[\mathrm{kg} / \mathrm{m}^{3}\right]$ the density, $h_{f}[\mathrm{~m}]$ the flow depth, $t_{i m p}[s]$ the impact 
duration, $h_{b}[m]$ and $b[m]$ the filling height and width of the barrier, $V\left[m^{3}\right]$ the released debris volume, $g\left[\mathrm{~m} / \mathrm{s}^{2}\right]$ the gravity constant and $\operatorname{Fr}[-]$ the Froude number $\left(F r=\frac{u}{\sqrt{g h_{f}}}\right)$.

The dimensionless quantity $\Pi_{1}$ describes the acting pressure $P_{\text {total }}$ compared to theoretical net drag, defined as the density $\rho$ multiplied with the velocity $u^{2}$. The parameter $P_{\text {total }}$ describes the pressure on the barrier and it has been obtained by the total load measured in flow direction divided by the impact area. $\Pi_{1}$ can therefore be interpreted as a dimensionless pressure coefficient. $\Pi_{2}$ represents the Froude number by being its inverse squared. It describes the ratio between kinetic energy and the potential energy for free surface flows. The time-dependent number $\Pi_{3}$ describes the length of the debris flow (impact time $t_{i m p}$ multiplied by the flow velocity $u$ ) compared to the filling height of the barrier $h_{b}$. Because this number describes the initial retention capacity of the net, it can be used to classify the tests. The number $\Pi_{4}$ is a scaled volume described as the release volume $V$ divided by the flow depth multiplied by the width of the chute $b . \Pi_{5}$ compares the fill height $h_{b}$ of the barrier with the flow depth $h_{f}$.

The range of $\Pi_{1}-\Pi_{5}$ for the small-scale laboratory tests and a full-scale implementation (e.g. the Illgraben torrent, see below) is shown in Table 2. The filling height $h_{b}$ is defined as the height of the flow surface above the lowest point of the barrier in the channel. The largest deviations are observed for the dimensionless volume $\Pi_{4}$ and the dimensionless length relation $\Pi_{3}$. These values could not be optimized because of the limited capacity of the laboratory release box and the geometrical boundaries of the test chute.

Another dimension-less number, the so-called Savage number (Savage and Hutter, 1989, 1991), has not been determined for neither laboratory tests nor the field material. It helps to evaluate whether the different flows are characterised more by gravity or by internal friction. However, the Savage number strongly depends on the grain sizes of the debris flows (Kowalski, 2008). Because of the grain sizes in the field were not determinable the Savage number has been left out for this analysis.

\subsection{Debris-barrier interaction}

The impact pressure $P_{d}$ (Fig. 8a) depended primarily on the front velocity $u$ and the discharge of debris through the net. It could be modelled accurately with the dynamic pressure formula

$$
P_{d}=c_{w} \rho u^{2}\left[N / m^{2}\right]
$$

Published by NRC Research Press 
Table 2. Dimensionless numbers describing the debris flow-barrier interaction process.

\begin{tabular}{llll}
\hline$\Pi_{i}$ & Description & Field tests & Laboratory tests \\
\hline$\Pi_{1}$ & pressure coefficient & $0.7-2.0$ & $0.1-1.0$ \\
$1 / \sqrt{\Pi_{2}}$ & Froude number* & $0.4-4.0$ & $0.7-7.0$ \\
$\Pi_{3}$ & flow length to $h_{b}$ & $2.6-4.0$ & $0.8-18.0$ \\
$\Pi_{4}$ & dimensionless volume & $120-700$ & $10-185$ \\
$\Pi_{5}$ & $h_{b}$ compared to $h_{f}$ & $1.6-8$ & $1.5-7$ \\
\hline
\end{tabular}

${ }^{*}$ The Froud number using Illgraben material was always below 2.0, material from the mountain Hasliberg produces Frounde numbers of up to 4.0.

with the pressure coefficient $c_{w}[-]$. The resulting total impact load $F_{d}$ per unit channel width can then be set to

[3] $\quad F_{d}=P_{d} h_{f}[N / m]$

For permeable nets with wire spacings greater than $d_{90}$ (grain diameter $d_{90}$ where $90 \%$ of the particles are smaller, from the cumulative grain size distribution) we found a difference in peak pressure $P_{\text {total }}$, depending on Froude number. At Froude numbers $\mathrm{Fr}>2$ the measured load on the barrier was primarily a function of the speed of the flow front. In this case the hydrostatic load per unit channel width, given by

$$
\text { [4] } \quad F_{s}=\frac{1}{2} P_{s} h_{f}=\frac{1}{2} \rho g h_{f}^{2}[N / m]
$$

is small in comparison to the dynamic pressure, with $P_{s}$ being the maximum hydrostatic pressure at the channel floor. For surge fronts with $\mathrm{Fr}<2$ as shown in Fig. 8a, the hydrostatic pressure component cannot be neglected. Thus, the laboratory tests suggest that the interaction between a debris flow and a barrier can be described as a hydraulic pressure if $F r>2$. The dimensionless number $\Pi_{1}$ then can be directly rewritten as by $\Pi_{1}=\frac{P_{d}}{\rho u^{2}}=c_{w}$. A Plot of $\Pi_{1}$ as a function of $F r=u / \sqrt{g h_{f}}$ is shown in Figure $8 \mathrm{~b}$ and indicates $\Pi_{1}=c_{w}$ values slightly higher than 0.5 for a (small) number of laboratory tests. Some larger values for $\Pi_{1}$ are due to the use of very viscous material taken of the river Trachtbach (Wendeler and Volkwein, 2015). Hence, the pressure coefficient depends on the debris material properties. Very viscous and granular flows result in larger pressure coefficients. Using $c_{w}$ ranging $0.7-0.9$ is on the safe side. Armanini and Scotton (1993) suggest pressure coefficients $c_{w} \approx 1-1.3$ for impacts in non-laminar flows obtained from small-scale test using plastic particles. Bugnion et al. (2012) reported $c_{w} \approx 0.2-0.8$ based on measurements during mudslide tests. Although 
Armanini and Scotton (1993) observed $c_{w}$ up to 2.0 for granular flow, our laboratory experiments never show values larger than 1 .

As written before the impact on rigid barriers produces smaller resulting loads in flow direction (with corresponding lower pressure coefficients) than on net barriers. This was explained after analysing the video records: In the laboratory experiments, with relatively large Froude numbers (largest Froude number shown in Fig. 8b), the rigid barrier mainly deviates the impacting flow upward and while the flow velocity changes direction, its magnitude remains large (see Choi et al. (2015) and Fig. 9a). In comparison, flexible barriers deformed upon impact and reduced the flow velocity in the downstream direction; the magnitude of the vertically-redirected velocity component at the net is much smaller. Therefore, the maximum total retention force measured at the sledge structure was larger for the flexible barriers than for rigid barriers for the same impacting flow. Hence, this also explains why $\Pi_{1}=c_{w}$ is smaller for impacts on rigid plates compared to retention by flexible nets.

Assuming Froude similarity we compare assumed total barrier stiffnesses $k_{m}$ in laboratory and $k_{n}$ in the field in relation to their impact areas $A_{m}$ and $A_{n}$ and the barrier deflections in flow direction $f_{m}$ and $f_{n}$ in relation to the flow depths $h_{f l, m}$ and $h_{f l, n}$ one can state that $\left(k * f / A * h_{f l}\right)_{m}$ should be equal to $\left(k * f / A * h_{f l}\right)_{n}$. In the laboratory we expect a deflection of about $f_{m}=0.1 m$ compared to the field with $f_{n}=2.5 \mathrm{~m}$. This length scaling of 25 compares favourably also for the relation of the flow depths. The relation of the barrier areas is about $A_{m} / A_{n}=1 / 400$. This results in a relation for the stiffness of the barriers of about $k_{m}=1 / 400 k_{n}$ which indicates that a barrier in the laboratory should be 400 times softer than in the field. This relation can only roughly be fulfilled even by the use of soft plastic meshes. We therefore did not attempt to link the elasticity and flexibility of the laboratory barriers to the full-scale ones. The dynamic behaviour of the barriers in the field, in combination of the reaction of the different barrier components, is too complex to be reliably replicated in the laboratory without additional research to verify the correct scaling of the individual components.

\subsection{Results from laboratory tests}

Laboratory tests are useful to study qualitative effects when a debris flow impacts a barrier. When quantitative aspects are considered scaling problems are a common issue when transferring smallscale laboratory results to the field (prototype) scale. In this case, also stiffness in the net does not scale realistically. However, with our dimensional analysis we were able to show that the impact pressure is 
Fig. 8. a) Impact pressures during laboratory experiments versus density and impact velocity. The line shows a linear regression between the total load measured and $P i_{1}$ with an inclination of 0.36 with the resulting coefficient of determination $R$. b) correlation between $\Pi_{1}$ and the Froude number $F r$.

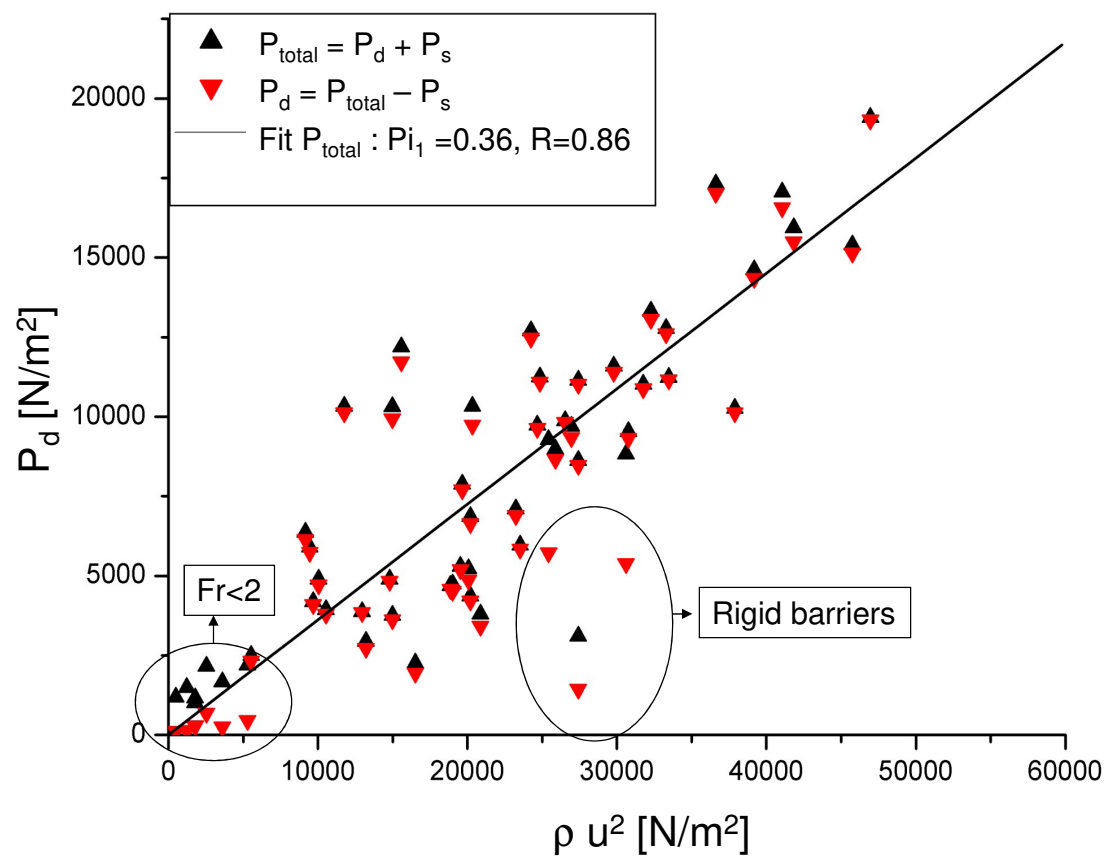

a)

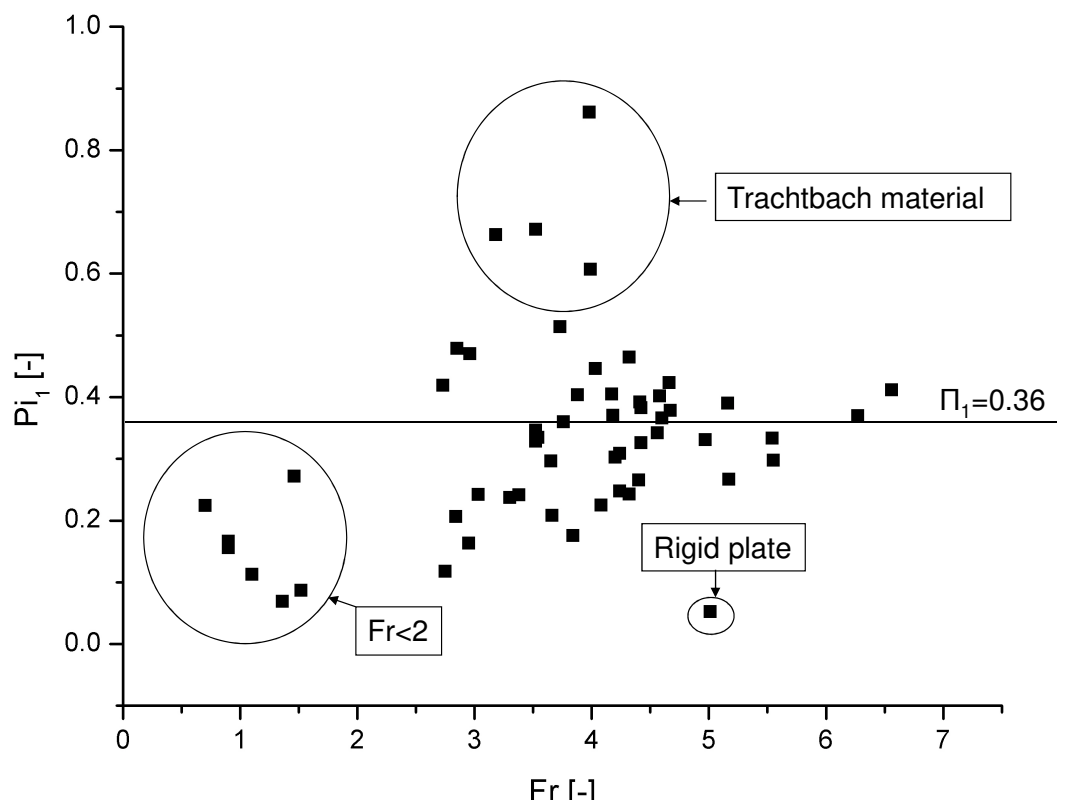

b)

$\operatorname{Fr}[-]$

a function of the pressure coefficient $\Pi_{1}=c_{w}$ and the impact velocity squared.

The stopping process is influenced not only by the stiffness of the barrier but also its geometrical 
Fig. 9. Two possible situations the debris material behaves after the first contact with a barrier: a) a fast flowing mixture with a higher water content hitting a rigid plate is deviated upward and overflows the barrier. b) The net structures slows the mixture down and an upstream directed reflected wave can be observed.
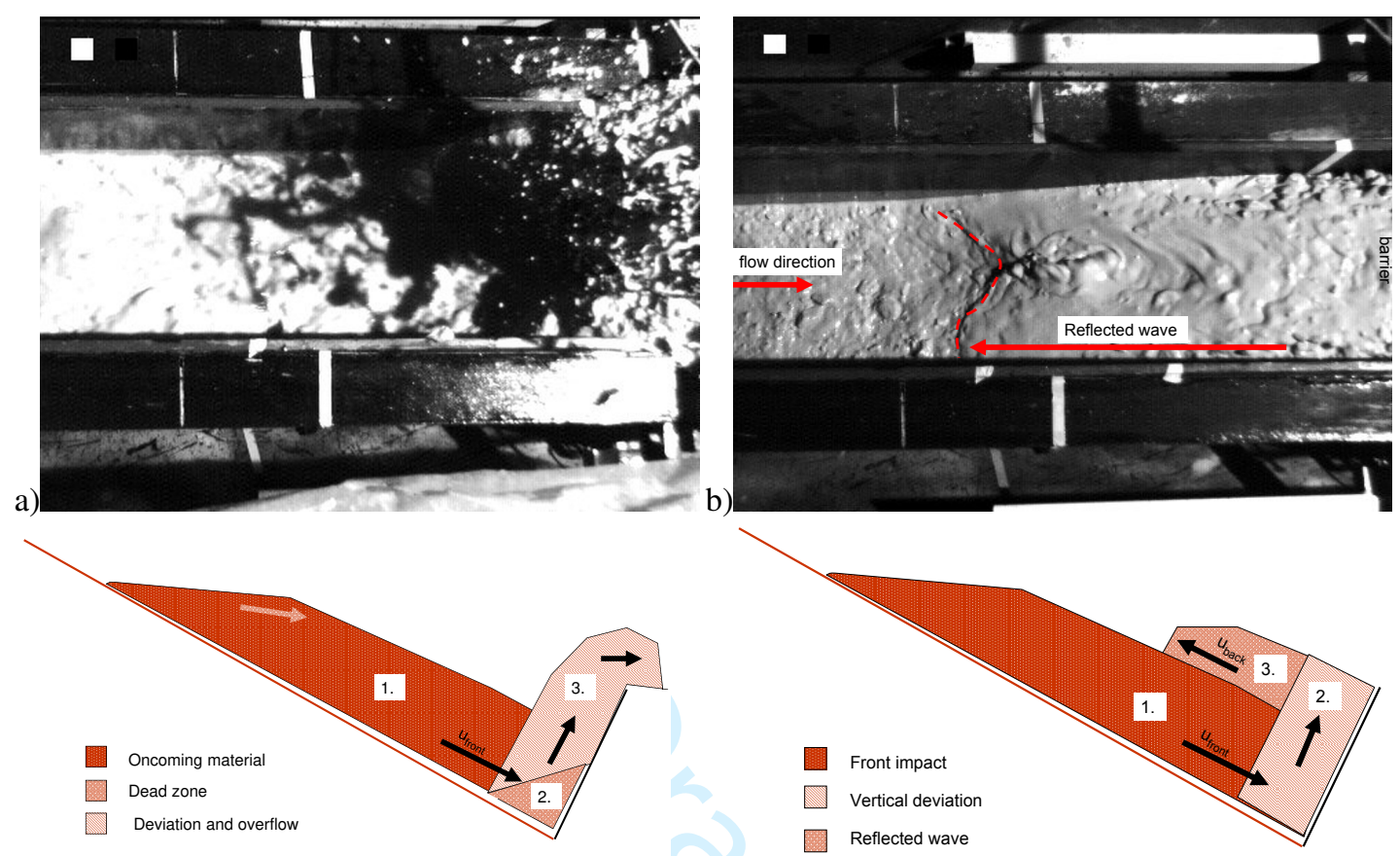

design. Larger particles in the flow can be trapped in the mesh that in turn gets clogged (e.g. described in Chevoir et al. (2012)). We investigated whether the pressure coefficients are a function of the mesh wire spacing (Wendeler and Volkwein, 2015). When the largest particles in the flow cause a blockage of the openings in the net (Fig. 3) the impact coefficient did not vary as a function of the size of the net openings anymore. We observed a partial blockage for particles with an diameter larger than half of the mesh aperture.

Another observation confirms the findings of Armanini and Scotton (1993) that slow moving, viscous or granular flows interacted with the barrier by showing a reflected wave after the impact (Fig. 9b).

Comparing the pressure coefficients from literature and our tests their range from $c_{w}=0.1-0.9$ is still very large when considering that this also results in a wide spectrum of possible loads on a barrier in the field. Therefore, based only on laboratory tests we estimate possible values for $c_{w}$ more as a scale for their theoretical magnitude in the field. Therefore, we suggest that laboratory results must be interpreted carefully to ensure that the physical processes in laboratory reflect the situation at full-scale. Field tests as described in the following section provide more reliability. 


\section{Full-scale field test site}

Full-scale field measurements with flexible barriers (Wendeler, 2008, 2016) were conducted at the Illgraben torrent, located in the Canton of Valais, near the municipality of Susten (Leuk), in the southwestern Swiss Alps. Historical data on debris flow activity at this site indicate that it is one of the most active catchments in the Alps (Rickenmann et al., 2001; Schuerch et al., 2006; Bennett et al., 2012). In the Illgraben, 2 to 7 debris flows or debris floods have been observed every year since the installation of the first instruments in the year 2000 (Hürlimann et al., 2003). Debris flows have occurred regularly during the last 100 years including many smaller events (volumes less than $75000 \mathrm{~m}^{3}$ ), five events with volumes ranging from 75000 to $250000 \mathrm{~m}^{3}$ and one event in 1961 with a total volume of about $500000 \mathrm{~m}^{3}$ (Badoux et al., 2009).

\subsection{Instrumentation}

The debris-flow barrier instrumentation was installed near the downstream end of the Illgraben channel, $50 \mathrm{~m}$ downstream of a large force plate and other instrumentation described by Berger et al. (2011). In this section, we first describe the existing observation station, and then we explain the instrumentation for the barrier in more detail.

The flow depth is measured at different locations using laser, ultrasonic, and radar devices (Badoux et al., 2009). The flow velocity is determined from the travel time between the flow depth sensors and/or geophone sensors, which are installed on check dams, and which generally allow clear detection of the arrival of a debris flow at a check dam. Additionally, basal shear and normal forces are measured using a large force plate installed below a roadway bridge (Fig. 10b, $50 \mathrm{~m}$ upstream of the barrier described herein). The force plate shown in Figure 10a and described by McArdell et al. (2007) is $4 \mathrm{~m}$ wide, $2 \mathrm{~m}$ long (in the flow direction). It was designed to measure bulk properties of the flow, such as basal shear force and normal force. Together with either the radar or laser flow-depth measurement above the force plate, it is possible to estimate the wet bulk density of the flow.

In 2006, a 14 m instrumented wall was constructed on the orographic left side of the channel several meters upstream of the large force plate (Fig. 10b). The instrumented wall consists of a vertical array of $0.3 \mathrm{~m}$ square force plates and three columns of six $0.3 \mathrm{~m}$ square geophone plates all mounted on a vertical wall which is nominally parallel to the direction of the flow. The force plates were intended to provide details on the pressure fluctuations at the boundaries in parallel to a debris flow (Berger et 
Fig. 10. Large-scale instrumentation at the Illgraben. Force plate (left image) used to measure normal and shear forces as well as flow density, and the instrumented wall (right image) with a small array of force plates, at the downstream (right) side of the wall to measure the pressure profile.

a)
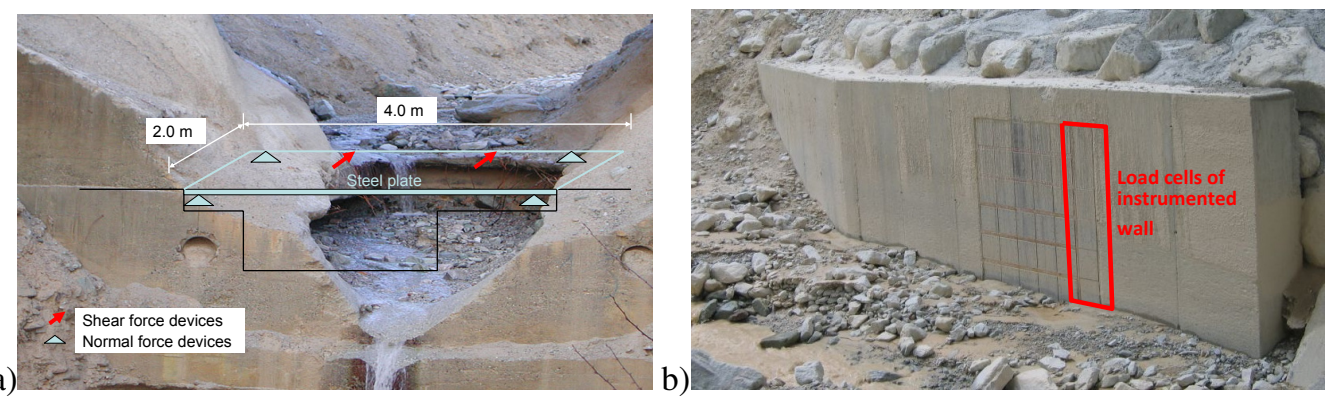

al., 2011), while the geophone plates were intended to provide information on the distribution of flow velocity as a function of height above the channel bed, through correlation of the impulses recorded on the plates, e.g. each plate is intended to function analogously to a Swiss plate geophone (Rickenmann and McArdell, 2007). We used the data of the instrumented wall to develop the load model presented. The interpretation of the measurements help to better understand the processes within a debris flow and can be used to indicate that e.g. that the pressure distribution within the approach flow is approximately hydrostatic.

Approximately $20 \mathrm{~m}$ before the Illgraben torrent enters the River Rhone, a test barrier was installed, roughly $50 \mathrm{~m}$ downstream of the shear and normal force devices. A video camera was placed downstream of the barrier to record each event in detail. Lighting devices were installed around the barrier to allow filming at night. Furthermore, the barrier was instrumented with a laser sensor (suspended overhead) to measure the flow depth and filling height over time upstream of the barrier. Load cells were installed in the support ropes to measure tensile stress (100 Hz sampling rate for all devices). Measured rope forces and filling height of one filling-overflow event in May 2006 are shown in Figure 11.

\subsection{Results of field measurements at the instrumented wall}

Because instrumented-wall data are not available for all of the events, we selected one event where the pressure profiles are clearly illustrated, i.e. where the flow depth is large enough to have impacted many of the plates in the vertical direction. Pressure profiles at the instrumented wall for 3 October 2006 event are reported in Figure 12 for three points in time: 1, 12 and $24 \mathrm{~s}$ after the front arrival. The values shown represent the $1 \mathrm{~s}$-average calculated from measurements with $2 \mathrm{kHz}$ sampling rate. Note 
Fig. 11. Rope forces of the barrier shown in Fig. 1c over time measured during a debris flow event on 18 May 2006 (see Table 3) together with the filling height of the barrier. The upper support ropes is a rope bundle defining the upper edge of the barrier. Correspondingly, the lower support ropes form the lower edge.

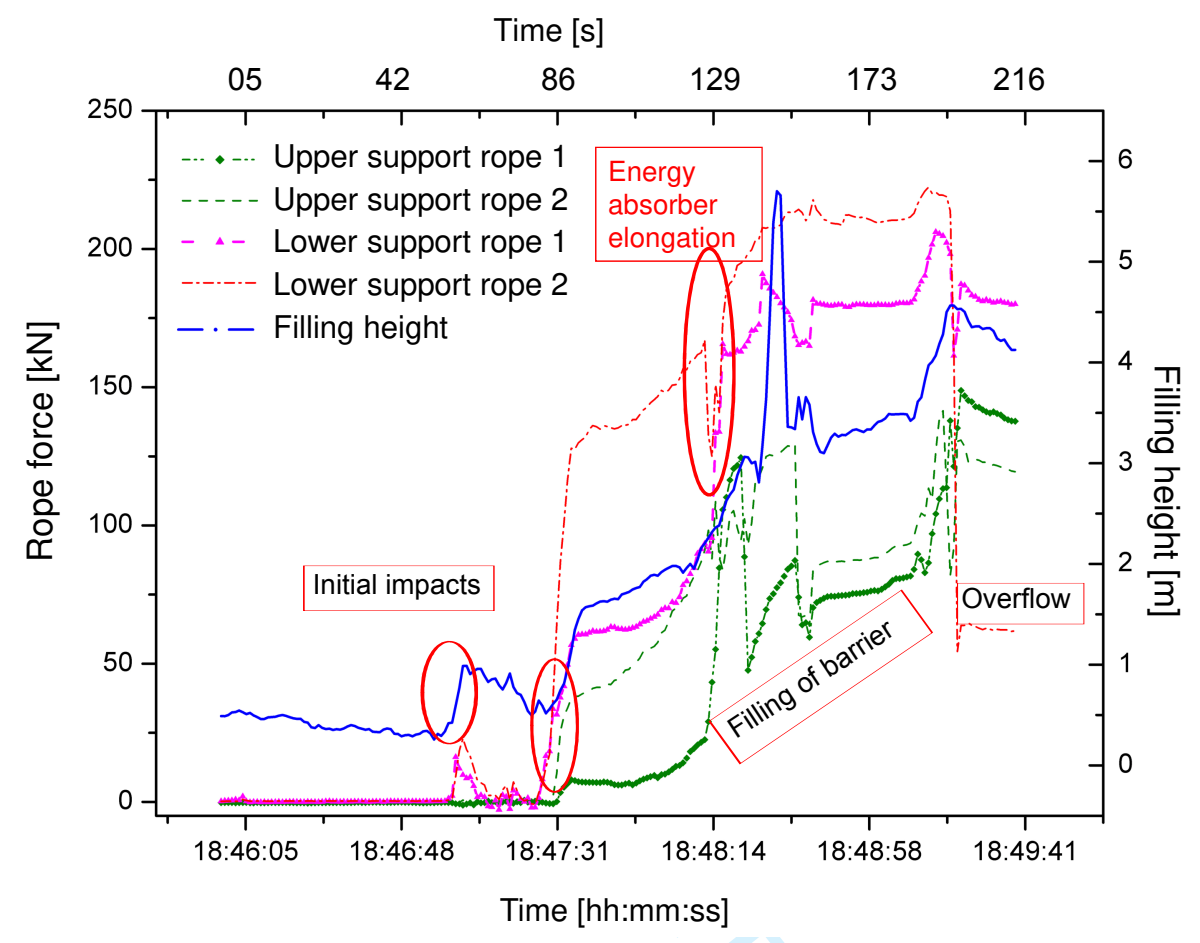

that load cell no. 2 , located near the bottom of the flow, was covered with sediment, a lateral levee from a previous debris flow, which effectively shielded the lower part of the wall from the debris flow. Because the pressure of cell no. 2 remained constant, we assume that the levee was not eroded by this event. At $\mathrm{t}=1 \mathrm{~s}$, the contribution of cells 5 and 6 to the structure response are moderate because the flow depth still increases. This increase of the front lasts about $8 \mathrm{~s}$ according from the video records at the shear wall. Considering these values as negligible with respect to that of other cells one might see a non-linear pressure profile. However, this observation is based on only 3 measurement points and should be considered to be somewhat speculative.

We interpret the data from this event at the instrumented wall as follows: the flow front appears to be homogeneous and well mixed, with water visible on the flow surface, suggesting that the flow is fully saturated. The video images also indicate that the particles present in the flow are cobbles and smaller-size sediments, with few larger boulders visible. We assume that there was no significant change in the flow between this location and the barrier downstream. The measured profiles at times 
Fig. 12. Pressure profiles for the 3 Oct. 2006 debris flow at different times on a rigid instrumented wall, $50 \mathrm{~m}$ upstream of the test barrier. The wall is oriented parallel to the flow and can be interpreted as representing hydrostatic (not impact) pressures. Each point shows the pressure recorded in average on $30 \mathrm{~cm}$ square plates. Load cell 6 is at the top of the wall, load cell 1 is buried in the channel bed and is not shown.

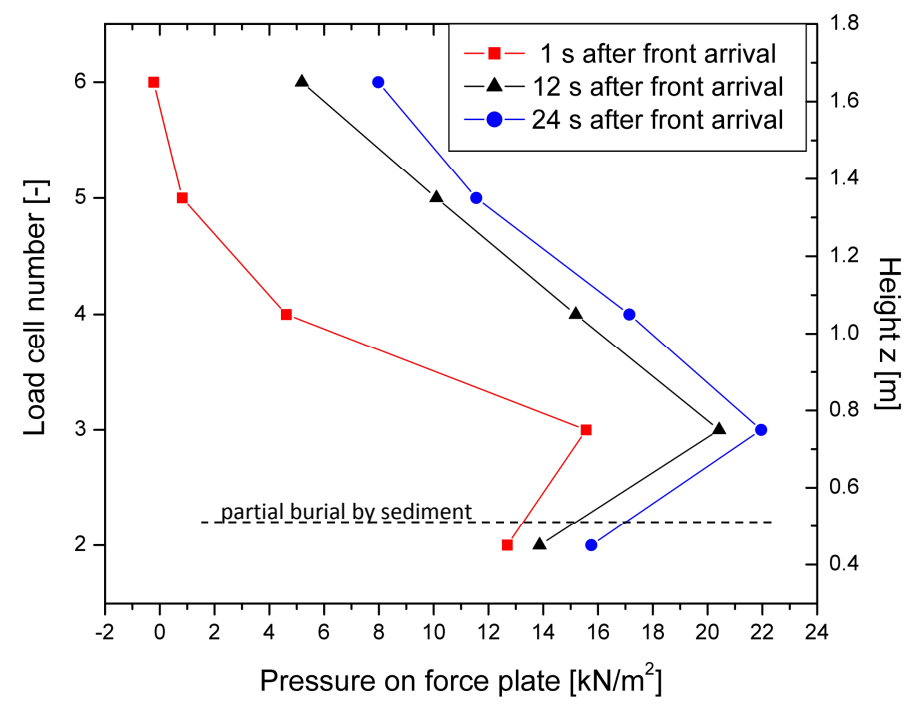

$12 \mathrm{~s}$ and $24 \mathrm{~s}$ are linear, indicating that a hydrostatic pressure profile was present during the flow, after the passage of the front. Because the surface level of the debris flow lays above the uppermost load cells, no qualified statement can be given whether the measured loads of cell 6 are related to also a dynamic or only a static pressure. As noted above, load cell 2 still is partly buried in sediment and therefore does not reflect the full acting load. Based on the data of $12 \mathrm{~s}$ and $24 \mathrm{~s}$ in Figure 12 the unit weight of the debris flow, which is the gradient of the upper curves (i.e. from the level of load cells nos. 3 to 6), can be estimated around $16 \mathrm{kN} / \mathrm{m}^{3}$. The density calculated at the large horizontal force plate from the normal force and flow depth is $2050 \mathrm{~kg} / \mathrm{m}^{3}$ (see Table 3). In a first approach we explain this difference that the debris flow does contain less blocks closer to the channel banks, i.e. the heavy blocks are concentrated more to the middle of the flow. Further, the size of the horizontal force plate with $4 \times 2=8 \mathrm{~m}^{2}$ is significantly larger than that one of the load cells $3-6$ with $0.3 \times 1.2=0.36 \mathrm{~m}^{2}$. For these reasons, the large plate is expected to provide a more realistic characterization of the mean density of the debris flow.

Between 2005 and 2008 a total of nine events impacted instrumented debris flow barriers (Wen- 
Wendeler et al., subm.

Table 3. Debris flow events stopped by the barriers. Debris flow velocity, flow depth, density and Froude number.

\begin{tabular}{|c|c|c|c|c|c|c|}
\hline Date & $\begin{array}{l}\text { Volume } \\
{\left[\mathrm{m}^{3}\right]}\end{array}$ & $\begin{array}{l}\text { Density } \\
{\left[\mathrm{kg} / \mathrm{m}^{3}\right]}\end{array}$ & $\begin{array}{l}\text { Front velocity } \\
{[\mathrm{m} / \mathrm{s}]}\end{array}$ & $\begin{array}{l}\text { Flow depth } \\
{[m]}\end{array}$ & $\begin{array}{l}\text { Froude no. } \\
{[-]}\end{array}$ & Front shape chronology \\
\hline 02 Aug 2005 & 6800 & 2100 & 6.0 & 1.0 & 1.91 & Granular/filling event \\
\hline 18 Aug 2005 & 4400 & 2200 & 0.7 & 0.8 & 0.25 & Granular/overflow \\
\hline 18 May 2006 & 15000 & 1600 & 2.9 & 1.0 & 0.93 & Muddy flood/filling \\
\hline 24 Jun 2006 & 50000 & 2000 & 6.0 & 2.7 & 1.17 & Granular/overflow \\
\hline 27 Jun 2006 & 55000 & 2000 & 4.9 & 2.6 & 0.97 & Granular/overflow \\
\hline 18 Jul 2006 & 10800 & 1900 & 7.9 & 2.5 & 1.60 & Muddy flow/overflow \\
\hline $28 \mathrm{Jul} 2006$ & 18000 & 2100 & 2.1 & 1.5 & 0.55 & Granular/overflow \\
\hline 03 Oct 2006 & 10000 & 2050 & 1.6 & 1.5 & 0.42 & Granular/overflow \\
\hline 18 Jun 2008 & 5000 & 2100 & 2.6 & 1.1 & 0.79 & Viscous mudflow/filling \\
\hline
\end{tabular}

deler $(2008,2016)$ and Table 3$)$. The events varied in velocity, flow depth and density (solid fraction). Both muddy debris floods and debris flows with large boulders were observed. However, no typical granular debris flow, with a comparatively small water content, impacted an empty net. Several events overtopped the barriers; several events activated the energy-absorbing elements which was apparent through a reduction in the supporting rope forces during the rapid plastic deformation of energy absorbers (Fig. 11).

\subsection{Measurements at the full-scale barrier}

The complexity of a debris flow impact on a flexible barrier and the intention to properly detect the different processes and parameters makes it difficult to obtain reliable results from field tests. Further, the efforts necessary for the installation of a single barrier and the great uncertainty regarding the date of the next natural debris flow limit the number of measurements. The different barriers that have been erected and all recorded debris flow events are listed in Wendeler $(2008,2016)$. This section describes the performance of a flexible barrier during the debris flow event on 18 May 2006 that filled the barrier. This event has been chosen as an example due to the high-quality data. Figure 11 shows the measurements of load cells within the support ropes and the measured filling height over time. On the left axis the loads between the ropes with the energy absorbers and the anchorage to the river banks is shown for the upper and lower support ropes anchored each on both river banks. The right axis is scaled for the measurements of the distance laser that was mounted over the river bed about $1 \mathrm{~m}$ upstream of the barrier. Related to the time-line we also marked the event characteristics that were visible from the video records. First, the debris flow passed underneath the barrier until reaching a flow 
depth that causes a reaction of the support ropes at about 18:47:05. The filling process started at about 18:47:35 with increasing forces in the ropes until about 18:48:12. Then, the load in the lower support rope reached about $160 \mathrm{kN}$ and at least one energy absorber was activated. During this activation the measured load drops significantly and afterwards increased again to further transfer the also increasing load. The elongation further enables the barrier to adapt its shape to the loading by deforming in flow direction and - at the same time - reducing its height. Similar load drops and therefore also elongations of the energy absorbers can be observed for the upper support ropes at about the times 18:48:20 and 18:48:40. After the time 18:49:05 the barrier was over-topped by another debris flow surge. A partial failure of one of the lower support ropes explains the significant load drop at that time.

We generalized the debris flow barrier impact in three steps (Fig. 11):

Initial impact: forces in the bottom support ropes increase rapidly (Fig. 11) and are a function of the flow density and velocity. As the net is deformed (stretched) by the impacting debris flow the total barrier height reduces from $H$ to a new height $H^{\prime}$ when fully filled.

Subsequent filling: forces in the ropes increase and energy absorbers get activated, primarily in the upper ropes as the backfill height increases. The measured rope forces are a function both of the dynamic impact as well as the static backfill height.

Overflowing: if the net height $H^{\prime}$ is not large enough to contain the volume of the entire debris flow, the body and tail of the debris flow will overflow the barrier. The upper support ropes experience an additional force exerted by the overflowing debris.

\section{Load model}

The procedure to define the load model reflects the full-scale test observations where the barrier has been filled continuously. The model discretizes this filling process over time. This results in three load cases: (1) the initial impact, (2) stepwise filling of the net and (3) the overflowing process. Each load case will be described in the following section. We will show that the net design algorithm is primarily a function of the velocity and flow depth $h_{f}$ of the filling steps. We assume the flow depth is constant for each step in accordance with the field measurements. Both dynamic pressure and static loads from the filling process are considered. We apply full active earth pressure pressure state calculated according to Rankine (1857) with an earth pressure coefficient $K=1$ which is on the safe side because we assume the material to be fully saturated and there are no experiences available yet whether and - if so - how 
much $K$ could be reduced regarding the drainage capabilities of the net.

In the field, the dynamic impact force usually varies over time according to the current flow depth and velocity. Muddy debris flows often have their maximum flow height not directly at the front compared to granular flows where the debris front has the largest flow depth and velocity of the entire debris flow. If we now take these two values constant for the complete debris flow during the filling process we stay conservative. The load model presented consists of hydrostatic and -dynamic pressures that in sum produce a pressure distribution non-linear over the filling height.

Pressure normally is directed always orthogonal to the surface it is acting on. However, due to the complex shape of a flexible barrier after deformation and the usability of our load model also for noncomputational design calculations we decided to apply the pressure only in the main flow direction.

\subsection{Alternative modelling approaches}

When transferring different load models into a discrete element simulation (Volkwein, 2005) the simulated rope forces can be compared with rope forces that have been measured during a field test. In total, three alternative load models were evaluated: 1 . assuming that the load acts evenly distributed over the entire barrier height and varies with time, 2. assuming that the still constantly distributed load only acts on the current active-flow layer (e.g. the depth of the debris flow, ignoring underlying deposits trapped by the barrier), and 3. assuming that the pressure varies over the current filling height. For the third case, we also tested three variants a,b, and c: a) assumed a hydrostatic distribution over the current filling height and the hydrodynamic pressure has been distributed evenly on the same height. b) assumed a stepwise filling of the barrier as described in section 4.2 including a scenario with overflowing debris material after the barrier has been fully filled. c) reduced the dynamic pressure to $50 \%$ because the filling material runs into the already stopped material which also has a braking effect. However, this simplified model did not fit the force measurements in the ropes well.

A fundamental assumption of the following design procedures is that we consider a two-dimensional cut in the $y-z$-plane at the net centreline (Fig. 13) because in the field we observed a filling of the barrier evenly-distributed over the width of the channel. Therefore, the variants described above do not consider variations of the acting pressures over the width of the riverbed. The model evaluation in section 5 assumes a constant parabolic pressure distribution over the channel width when analytically deriving the rope forces in section 5.1. An alternative load model presented in Brighenti et al. (2015) 
differs from the model presented above. It varies the pressure along a circular arc to the lower centre of the barrier's edge.

\subsection{Modelling approach}

The development of the chosen load model is based on an analysis of the rope forces measured during the nine events reported in Wendeler $(2008,2016)$. The load model mainly describes pressure loads that act on the barrier and that vary over the height above the channel bed and over time. The following sections describe the load model that has been developed.

\subsubsection{Initial impact: stopping the debris flow front}

The debris flow first impacts the barrier and will be stopped when the flow depth $h_{f}$ is greater than the height of a basal opening $h_{\text {basal }}$ (see Fig. $1 \mathrm{~b}$ and Fig. 13a). The laboratory tests revealed that the basal height ideally is $h_{\text {basal }} \leq \frac{2}{3} h_{f}$, i.e. two-thirds of the expected initial maximum flow depth. The initial maximum front flow depth is difficult to predict. At the Illgraben, events have been observed with maximum front flow depths ranging from a few decimetres up to $3 \mathrm{~m}$. In addition, torrents containing wood debris and large boulders will increase the flow depth and may initiate an earlier stopping/filling process after the initial impact.

The total load $P$ during the initial impact is composed by a hydro-static $\left(P_{h y d}\right)$ and a hydrodynamic part $(\Delta P)$. The dynamic force acting on the net during the first impact is $F_{d}=c_{w} \rho h_{f} u^{2}$ per unit channel width where $c_{w}$ - the pressure coefficient - depends on the flow material and its properties. It ranges between $c_{w}=0.7$ for debris floods (relatively small sediment concentration) and $c_{w}=1.0$ for more viscous type mud/debris flows. Armanini and Scotton (1993) use $c_{w}=2.0$ for impact of granular flows on rigid obstacles. The hydrostatic force per unit channel width is $F_{s}=\frac{1}{2} K \rho g h_{f}^{2}$ (with $K=1)$.

Stress concentrations, indicated by pressure coefficients $c_{w}>2$, have been observed in other geophysical mass movements composed of granular material, e.g. wet snow avalanches, when impacting slender objects. This effect can be explained that an obstacle with a cross-sectional area exposed to the flow area not only influences a flow area of the same size but also the flow in the nearest neighbourhood. So, at small impact speeds objects of small width (defined relative to the flow width) will experience pressure forces greater than those predicted by the dynamic pressure formula used in our 
loading analysis procedure. This effect is not considered within this contribution. However, for a barrier design care must be taken for e.g. slender columns, supports or other structural components exposed to the flow, especially when designing for granular debris flows. Muddy debris flows containing little solid fraction cannot redistribute the impact forces, cause less material jamming, and therefore probably do not constitute as large of a threat to exposed components. The designer should keep in mind, that above effect is relevant only for slender objects, for large obstacles such as the whole net area of a barrier this effect is neglectable.

\subsubsection{Subsequent filling steps}

After the initial impact and with the mass stopped we assume a remaining hydrostatic pressure distribution of filling height $h_{b}$. This is somewhat conservative because we assume the stopped material does not drain quickly. In reality, water will pass through the net, reducing the hydrostatic pressure over time.

For the subsequent filling of the barrier, we assume that the first impact of the debris flow has not filled the barrier and that the flow continues after the initial impact. The pressures acting on the barrier are composed of both the static load of the material and the dynamic load of the following oncoming material. In our load model (Figure 13b) we made two assumptions/simplifications: the filling process is discretized into individual in-filling steps, the duration of which depends on the thickness $h_{f}$ of the in-filling debris-flow mixture. Additionally, we assume that the dynamic pressure acts only on the thickness considered in the individual in-filling step while the hydrostatic pressure acts over the entire fill-height $h$ of the barrier (including material which stopped in previous in-filling steps, Figure 13b). The height of this top part equals the filling step size, i.e. the flow depth $h_{f}$. The drag force acting on the barrier therefore is $F_{d}=c_{w} \rho h_{f} u^{2}$ per unit channel width; i.e. it is equal to the dynamic pressure of the initial step, but now with elevated point of loading. The hydrostatic force per unit channel width is the sum of all filling steps: $F_{s}=\frac{1}{2} K \rho g h^{2}$ (with $K=1$ ). The third or even more steps are considered in the same way until the maximum barrier height is reached (the original height of the barrier might be reduced in filled state).

We use the same density for both the hydrostatic and hydrodynamic pressure, i.e. that of the flowing material. Of course, once the debris has been stopped and drains its density changes. However, the magnitude of the static pressure then could be reduced because the drained material remains more 
stable than a rather liquid debris mixture. This would load the barrier less from a static point of view. We assume that the draining process is slow in comparison to the rate at which the barrier is filled, so we do not consider this effect. Therefore, we remain conservative if we apply the hydrostatic pressure with the density of the mixture.

The numeric value of the hydrostatic maximum pressure itself is not necessarily larger than the hydrodynamic pressure. However, at least for the cases described herein, the area the static pressure is acting on makes it the dominant load. For example, a barrier being already filled up to a height of $5 \mathrm{~m}$ and being additionally overtopped with a $1 \mathrm{~m}$ flow depth has a maximum hydrostatic pressure at its bottom of $P_{h y d}=130 \mathrm{kN} / \mathrm{m}^{2}$. The hydrodynamic pressure is $\Delta P=149 \mathrm{kN} / \mathrm{m}^{2}$ (velocity = $5.8 \mathrm{~m} / \mathrm{s}$, density $=2200 \mathrm{~kg} / \mathrm{m}^{3}$, flow depth $=1 \mathrm{~m}, K=1, c_{w}=2$ ). So, per meter width of the channel a hydrostatic load of $F_{h y d}=0.5(5+1) 130=390 \mathrm{kN} / \mathrm{m}$ comes with a hydrodynamic load of "only" $F_{d}=149 \mathrm{kN} / \mathrm{m}$.

Due to the flexibility of the barrier, both the shape of the barrier and the barrier height will change during an in-filling event. The resulting reduced barrier height $H^{\prime}$ therefore influences both the maximum acting pressures and the total volume being retainable by the barrier. The field experiments show a height reduction of $25 \%$, i.e. the lowest elevation of the upper barriers edge above the ground after the barrier has fully been filled is $75 \%$ of the original position before the event.

The barrier presented in Volkwein et al. (2015) and shown in Figure 14a, b has in total 10 levels of support ropes. The ropes are not spanned straight across the channel but follow a radial circumference. The loading conditions are a discharge of $200 \mathrm{~m}^{3} / \mathrm{s}$ traveling at $u=7 \mathrm{~m} / \mathrm{s}$ with a material density of $\rho=2200 \mathrm{~kg} / \mathrm{m}^{3}$. The dynamic pressure then results to $P_{d}=216 \mathrm{kN} / \mathrm{m}^{3}$ with a pressure coefficient of $c_{w}=2.0$. Applying above load scheme over time (including a safety factor of 1.3) illustrates the discretized filling process (Fig. 14c) and its influence on the effective single rope forces (Fig. 14d). In the beginning only the lower ropes are loaded. As the barrier is filled the higher-positioned ropes are then also loaded. The figure also shows a load redistribution in the vertical direction: debris hitting the lower area of the barrier not only stresses ropes at the lower portion, but also on higher levels due to the movements and load transfer of the net in flow direction. The uppermost rope does always have a low rope force according to the simulation due to its geometrical arrangement with the pre-defined rope sag: when the debris level reaches the lowest part of the upper support rope the debris immediately goes over the rope and does not fill the barrier further.

Published by NRC Research Press 


\subsubsection{Overflowing process}

The design procedure considering multiple steps continues until the barrier is completely filled. Moreover, $H^{\prime}$ defines the number of steps $n$ of flow depth $h_{f}$ the barrier can withstand: $\mathrm{n}=H^{\prime} / h_{f}$. The $(n+1)^{t h}$ step flows over the barrier exerting a normal load $\sigma$ and shear stress $\tau$ (see Fig. 13c), primarily on the upper ropes. Measurements at the Illgraben force plate showed that the shear load $\tau$ is only about six percent of the vertical stress $\sigma$ (Wendeler, 2008, 2016) and therefore is neglected. The hydrostatic pressure $P_{s}$ is increased by the self-weight of the overflowing material resulting in a stress component $\sigma$ that is directed downward. We assume that the stopped material is not yet drained and therefore we fully add $\sigma=\rho h_{f} g$ to the hydrostatic pressure. Clearly, the validity of this assumption depends on the drainage properties of the debris material. In August 2005, we observed the failure of a lower support rope when a barrier was impacted by a viscous debris flow, with poor drainage properties. However, for a long filling time and well-drained sediment, which often includes relatively small amounts of silt and clay sediments, the pressure behind the barrier can be reduced using an appropriate earth pressure coefficient. This possibility is marked by the red dotted line in Figure $13 \mathrm{c}$.

\section{Model evaluation}

The model was tested using the event recorded in May 2006 (Table 4). The measured rope forces for the filling event in 2006 are shown in Figure 11. The measured density of the flow using data from the force plate was relatively low for a debris flow with $\rho=1600 \mathrm{~kg} / \mathrm{m}^{3}$ so that a mud flow pressure value $c_{w}=0.7$ was assumed. Comparison with video images suggests that this assumption is valid, because only few large boulders were visible in the flow. With the model of pressure steps the forces shown in Table 4 act on the rope equally distributed over the channel width as shown in Figure 15, option 1. In fact, we received the best results assuming a triangular load distribution over the channel width as shown in Figure 15, option 2. However, by assuming option 1 the load model will stay on the safe side.

\subsection{Analytical determination of rope forces}

The idea behind the rope equation (Palkowski, 1990) is that the tension decreases as the length of the rope increases (assuming that the endpoints remain fixed). In our case, to further reduce the maximum load (tension) on the rope, plastically-deforming energy-absorbing elements are used. In the 
Fig. 13. Filling of a debris barrier discretized over time: (a) Initial debris flow pressure loading step the bottom support ropes; (b) Follow-up debris flow steps acting on the barrier; (c) Overtopping stage with the influencing forces $\sigma$ and $\tau$ on the stopped material. The dashed lined at the hydrostatic pressure distribution indicates that after a certain time - the deposited material might have been settled and the magnitude of the hydrostatic component might be reduced as an active earth pressure according to Rankine (1857).

The figure labels the pressures $P$ acting per area unit. For the design of a barrier the acting total forces $F$ in the vertical and horizontal areas distributions have additionally to be considered.

a)
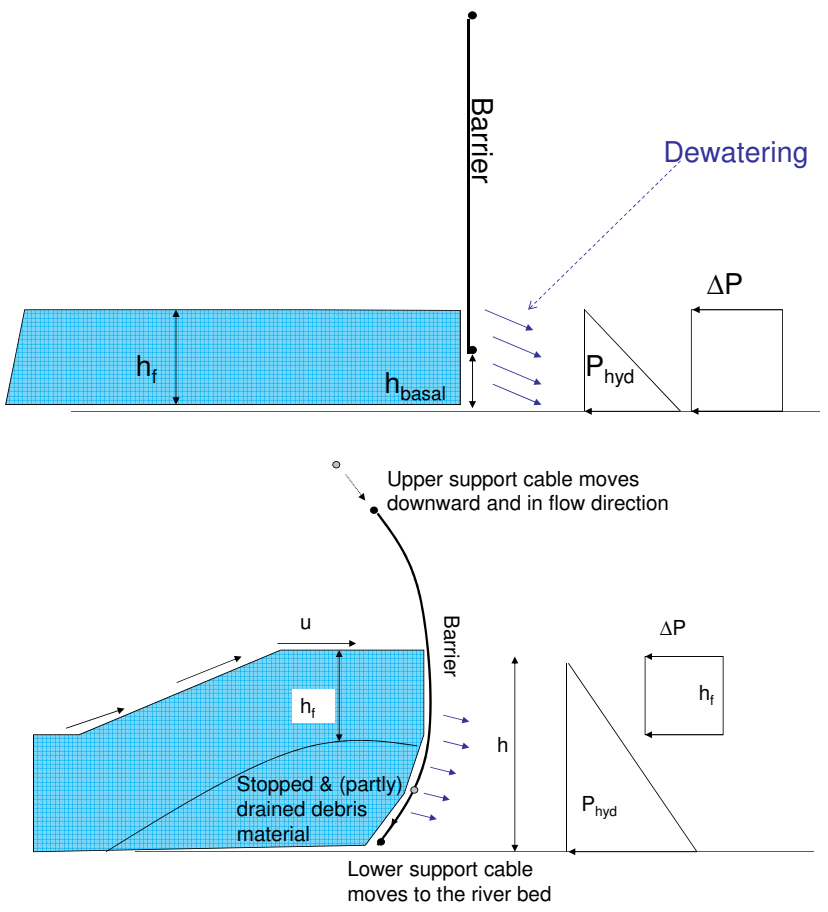

b)
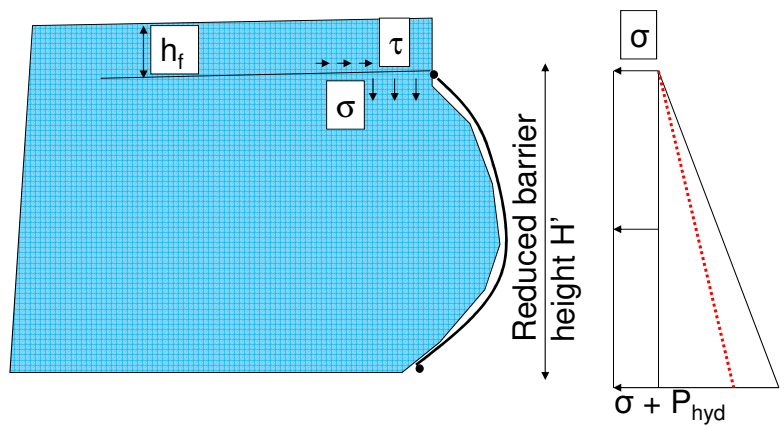

c)

barrier described in this manuscript, the rope is looped through a hollow steel ring which can deform under loads approaching the rope strength. Consequently the ropes effectively elongate under peak loads rather than breaking, with some force going into plastically deforming the additional elements.

We now back-calculated the rope forces using different pressure distributions acting on the net. 
Fig. 14. Example for the evolution of the modelled acting pressures over time on a barrier with curved support ropes (Volkwein et al., 2015): a) installed barrier and b) drawing for the support at the riverbanks and support ropes. c) The upper section of each small image visualizes the assumed dynamic pressure with an additional hydrostatic component. The lower part shows the assumed hydrostatic pressure of the already stopped material. In the last image the overflow condition is visualized composed from a hydrostatic pressure distribution with an additional component constant over barrier height modelling the influence of the debris flow going over the barrier. d) Evolution of support rope forces over time. The barrier modelled has ten support ropes (diameter $=95 \mathrm{~mm}$ ) with rope 1 located at the bottom edge of the net.

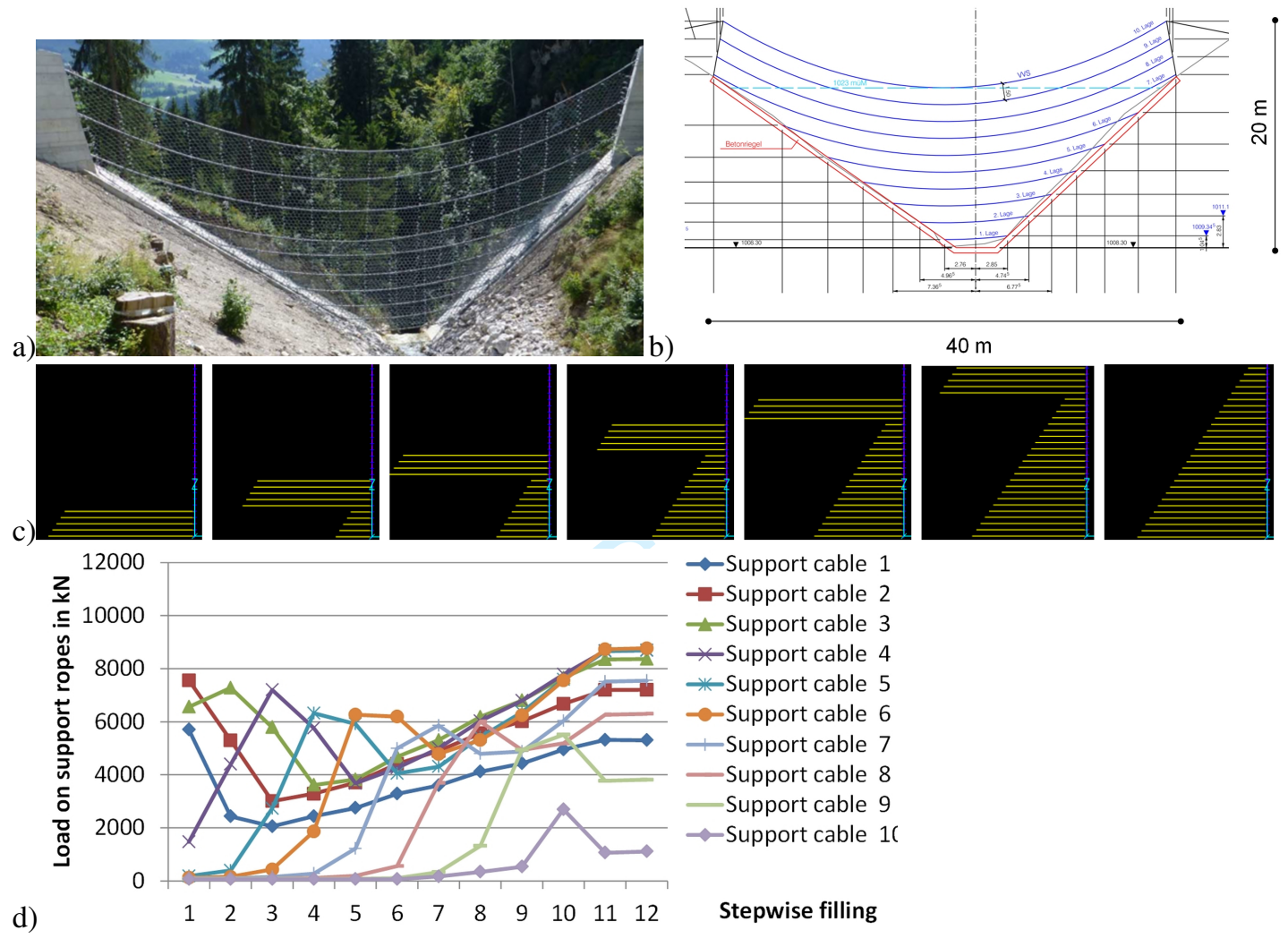

These pressures are distributed as line loads on all ropes that are spanned over the river channel and structurally can take over the loads. The direction of the ropes is along the width of the net in the $x$-direction which is the rope's original longitudinal direction (see Fig. 15). To now obtain the rope forces the differential rope equation is solved using a Newton iteration method (Palkowski, 1990): The approach assumes a rectangular, triangular or parabolic line load and determines the corresponding rope force. Special attention has to be paid to the elongation $l_{b r}$ of the energy-absorbing elements (brake rings). They also elongate and therefore require a consideration within the force-lengtheningiteration to solve the rope equation. In our case, we determined the lengthening of an energy absorber according to its force-elongation diagram that has been obtained from quasi-static tension tests. The 
Table 4. Measured vs. modelled rope forces during a mud flow event for different kinds of filling levels as shown in Figure 13

\begin{tabular}{lllll}
\hline Chronology & Ropes & Measured load $[\mathrm{kN}]$ & Model result $[\mathrm{kN}]$ & Comments \\
\hline \multirow{2}{*}{ First initial step } & Bottom ropes & 85 & 90 & Top ropes not yet influenced by model \\
& Top ropes & 25 & 0 & \\
Second step & Bottom ropes & $125-150$ & 144 & Top ropes not yet influenced by model \\
& Top ropes & 65 & 0 & \\
Third step & Bottom ropes & 200 & 200 & Nearly identical \\
& Top ropes & 120 & 135 & Overestimation for overflow \\
\hline \multirow{2}{*}{ Third step } & Bottom ropes & 225 & 240 & \\
& Top ropes & 150 & 170 & \\
\hline
\end{tabular}

absorber's elongation is then distributed as an evenly distributed strain/elongation along the full rope track. The iterative procedure to solve the rope equation works as follows (Volkwein, 2014): 1. calculate the length of the rope (incl. energy absorbers); 2. solve rope equation to obtain rope force based on acting line load; 3. calculate rope strain and dissipater elongation based on rope force; 4. re-calculate the length of the rope; 5 . repeat above scheme until the length of the rope stops elongating.

The results of the back-calculation using the rope equation showed that the triangular-shaped load distribution fits the measured deformations (suggesting a corresponding velocity distribution over the channel width). The rectangular load distribution models the measured stopping loads in the rope best, although the maximum deformations $f$ are slightly underestimated (Wendeler, 2008). Because we are interested in the structural capacity, we assume a rectangular load distribution and hence a twodimensional net section in the design procedure. This simplifies the design procedure considerably because a three-dimensional analysis is not necessary.

\subsection{Comparison of rope forces}

For the 18 May 2006 event the observed flow velocity was $u=3 \mathrm{~m} / \mathrm{s}$ and the maximum front flow depth $h_{f}=1 \mathrm{~m}$. The time when barrier overflowing starts is seen in the video records, and the number of filling steps $n$ can be calculated using $H^{\prime} / h_{f}$. Applying the multi-step model to each back-filling stage we calculated the rope forces using the differential rope equation. The deformations of the energy absorbers and the rope forces predicted by the load model agree well with the field measurements. In the two first load steps the forces in the upper support ropes are underestimated by $100 \%$, because the load model assumes that they are not influenced by the load applied at the base of the net: the load model only assumes a horizontally acting pressure. However, the tension in the lower net section is also 
Fig. 15. Conversion of a distributed load that acts on a curved rope. The load distribution $q_{(x)}$ along the rope track $s$ can be shaped differently (1=evenly, $2=$ triangular, $3=$ parabolic). The detail sketch in the lower part visualizes how the differential rope equation can be found by formulating the static equilibrium equations for one part of the rope.

Legend: $F_{\text {rope }}=$ rope force; $H=$ lateral component of rope force; $\phi=$ angle rope along its track in load direction measured orthogonally to a connection line between the rope ends.

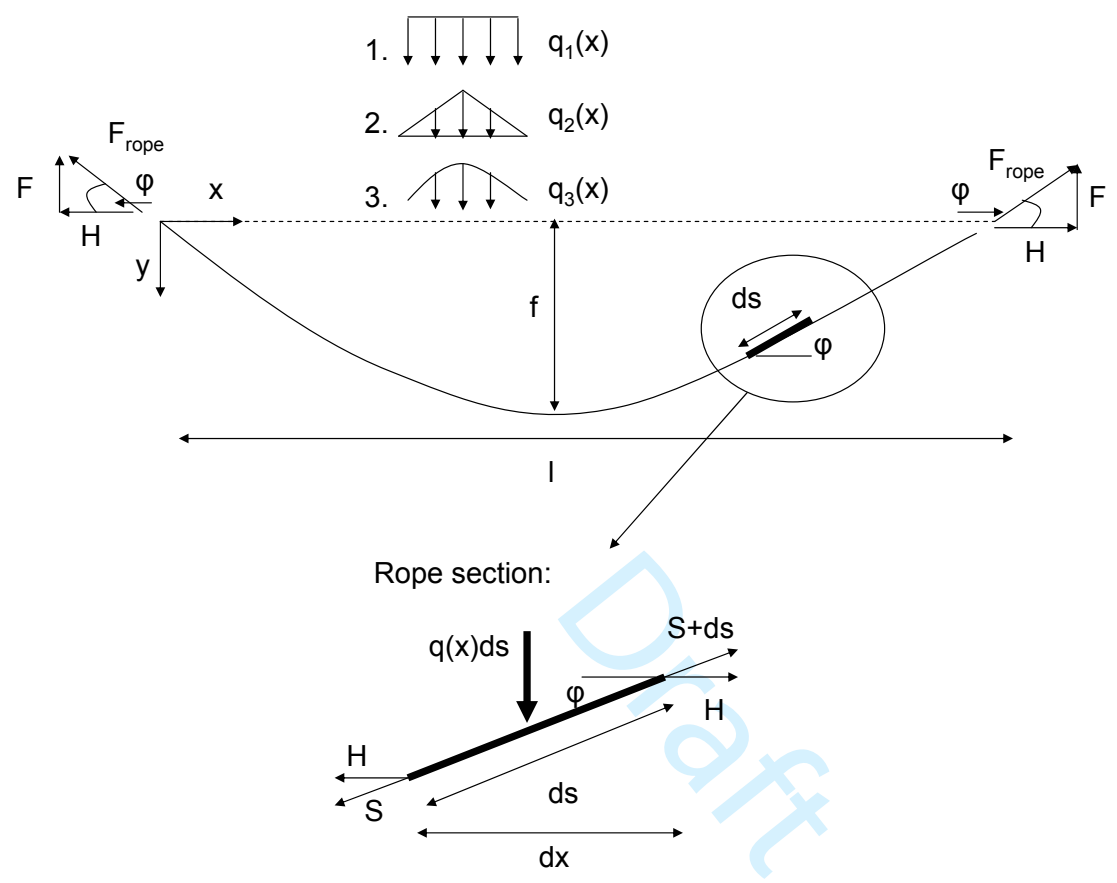

forward, i.e. in flow direction. This forward deformation tensions the net also at the top edge resulting in a force in the top support ropes. This effect is not included in the load model because these loads are clearly smaller (18\%) compared to that of the subsequent filling steps. The lower support ropes can be modelled well for the initial steps (see Fig. 13 and Table 4). The third step describes all measured forces correctly (on the lower and upper ropes) before the maximum filling level of the barrier is reached and the overtopping process begins. From this point on, the model overestimates the measured rope forces by up to $21 \%$.

\subsection{Outlook}

Considering the above details it should be possible to dimension and design flexible barriers in torrents against debris flows. Meanwhile, the load model described herein has been shown to be useful for the design of flexible barriers in Hong Kong, see Kwan and Cheung (2012), and Switzerland 
(Volkwein, 2014; Wendeler et al., 2014). The use of the proposed model in engineering design may eventually result in the development of a suitable design procedure. However, first accurate pressure coefficients have to be predicted (Canelli et al., 2012; Brighenti et al., 2013; Kwan et al., 2014). Examples as shown in Kwan et al. (2014) already show the principle usability to model the filling process.

The load model now also can be implemented in finite element software for the structural analysis of ringnet barriers, e.g. FARO (Volkwein (2004) in German; Volkwein (2005) summary in English). This software was originally developed for flexible rockfall barriers containing the same structural components - ringnets, support ropes, energy absorbers and anchors. The software has been extended to include the distributed debris flow loads, rather than the highly dynamic and concentrated rock fall impacts. This makes the calculation of forces in these barriers efficient to handle by hazard engineers.

Of course, the up to now rather simplified model presented can be improved using advanced numerical methods. E.g. the interaction of debris flow and barrier nowadays perfectly can be modelled using Fluid-Structure-Interaction (FSI) codes as shown in Boetticher (2013), Albaba (2015) or Leonardi et al. (2016). These coupling simulations promise best results if paired with simulations of the debris flows using special codes such as the RAMMS model (Christen et al., 2012). Further testing of course helps to clarify more clearly the drag effects from real material (mostly granular range). A possible reduction of the acting earth pressure compared to a full pressure using an earth pressure coefficient $K=1$ can be studied through additional field measurements especially if the barrier is overflown by the debris flow. The de-watering capabilities of the barrier probably will have a large influence. Further, the current model fully neglects time influence during the filling process which can be improved. Additionally, the static weight of the debris is not considered up to now because we assume that the filled barriers might fully rest on the ground. However, different structures will require to take the selfweight into account. For example, this would be the case, if a net barrier is placed along the front edge of a concrete check dam.

\section{Summary}

We described the development of a simplified model for designing flexible debris flow barriers. The significant parameters for a load model were obtained from laboratory tests and an according dimensionless analysis. The well-fitting load model was chosen by comparing predicted forces in the support ropes with the measurements within a full-scale net barrier during debris flow events in a 
natural river channel. The two cornerstones of the design procedure are the assumptions of a dynamic drag proportional to the velocity squared and a hydrostatic pressure distribution within the flow at rest and during motion.

We estimate the obtained pressure coefficients obtained from laboratory tests as suitable to evaluate the laboratory experiments. However, for field conditions we recommend to handle such coefficients carefully, because there are not yet field measurements available for comparison. So, there are not yet sufficient independent measurements to confirm or refute the different scaling approaches. We therefore recommend a more conservative approach with a coefficient of $c_{w}=0.7$ for mud flows and 2.0 for granular flows.

When a debris flow is confronted with a barrier spanning the torrent width, we assume the applied load is evenly distributed over the barrier. This result is derived from the back-calculation of the rope forces and deformations. It appears that stress concentrations induced by debris jamming, or other force redistribution mechanisms, are therefore compensated considering the influence on the total area load.

The pressure distribution is largely hydrostatic. It can be seen in Figure 11 that the loads measured in the field increase over time when the barrier gets filled. Due to the fact that the oncoming debris has an approximately constant flow depth after the arrival of the flow front it exerts a constant hydrodynamic load. Hence, the increase of the loads in the support rope of a flexible barrier is mainly dominated by the already stopped debris in the net. The normal pressures are primarily a function of the flow depth and density. The selection of an appropriate density might therefore be one of the most uncertain parameters in the design procedure.

\section{Acknowledgements}

The authors would like to thank the Swiss Federal Commission for Technology and Innovation (KTI/CTI) for the partial financial support within the project Numerical Modelling and Dimensioning of Flexible Debris Flow Barriers (7493.2 EPRP-IW). Many thanks for the realization of the measurement techniques go to Bruno Fritschi, WSL. The laboratory tests initially have been setup by Florian Kaineder during an internship. We further thank Andreas Gubler and Magdalena Schlickenrieder for their support and master theses. We are grateful for the comments of the reviewers which significantly improved the manuscript.

Published by NRC Research Press 


\section{References}

Albaba, A. 2015. Modélisation par éléments discrets de l'impact des laves torentielles granulaires sur des structures rigides et flexibles. PhD-theses, Université Grenoble.

Ashwood, W.. and Hungr, O. 2016. Estimating total resisting force in flexible barrier impacted by a granular avalanche using physical and numerical modelling. Can. Geotech. J. 53(10):1700-1717.

Armanini, A. and Scotton, P. 1993. On the impact of a debris flow on structures, in: Proceedings of XXV Congress of International Association for Hydraulic Research, IAHR, Tokyo.

Badoux, A., Graf, C., Rhyner, J., Kuntner, R., and McArdell, B.W. 2009. A debris-flow alarm system for the Alpine Illgraben catchment: design and performance. Nat. Hazards 49: 517-539.

Bennett, G.L., Molnar, P., Eisenbeiss, H., and McArdell, B.W. 2012. Erosional power in the Swiss Alps: charcterization of slope failure in the Illgraben. Earth Surf. Process. Landf. 37: 1627-1640.

Berger, C., McArdell, B.W., Schlunegger, F., 2011. Direct measurement of channel erosion by debris flows, Illgraben, Switzerland. J. Geophys. Res. 116, F01002, doi: 10.1029/2010JF001722: 18 p.

Bichler, A., Yonin, D., Stelzer, G. 2012. Flexible debris flow mitigation: introducing the 5.5 mile debris fence. In: Eberhardt E, Froese C, Turner AK, Leroueil S (eds) Landslides and engineered slopes: protecting society through improved understanding. CRC Press, New York, pp 1955-1960

Boetticher, A. 2013. Flexible Hangmurenbarrieren: Eine numerische Modellierung des Tragwerks, der Hangmure und der Fluid-Struktur-Interaktion. PhD-thesis. TU Munich, ISBN 978-3-8440-1616-1.

Brighenti, R., Segalini, A., and Ferrero, A. M. 2013. Debris flow hazard mitigation: A simplified analytical model for the design of flexible barriers. Computers and Geotechnics, 54; 1-15.

Brighenti, R., Ferrero, A.M., Segalini, A., Umili, G. 2015. Study on the Mechanical Behaviour of Flexible Barriers by in situ Testing and Modelling in: Lollino, G., Giordan, D., Crosta, G., Corominas, J., Azzam, R., Wasowski, J., Sciarra, N. (Eds.) Engineering Geology for Society and Territory - Volume 2 (Landslide Processes), pp 1651-1655.

Bugnion, L., McArdell, B.W., Bartelt, P., Wendeler, C. 2012. Measurements of hillslope debris flow impact pressure on obstacles. Landslides 9: 179. doi:10.1007/s10346-011-0294-4.

Published by NRC Research Press 
Canelli, L., Ferrero, A. M., Migliazza, M., and Segalini, A. 2012. Debris flow risk mitigation by the means of rigid and flexible barriers - experimental tests and impact analysis. Nat. Hazards Earth Syst. Sci., 12, 1693-1699.

CGS. 2004. Design code for debris flow disaster mitigation measures, DZ/T0239- 2004. (Draft). China Geological Survey. [In Chinese.]

Chan, S.L., Zhou, Z.H., Liu, Y.P. 2012. Numerical analysis and design of flexible barriers allowing for sliding nodes and large deflection effects. In: C.K. Lau, E. Chan and J. Kwan (Eds). Proceedings of the One Day Seminar on Natural Terrain Hazards Mitigation Me.

Chanut, B., Faug, T., and Naaim, M. 2010. Time-varying force from dense granular avalanches on a wall. Physical review E, 82(4), 041302

Chevoir, F., Gaulard, F., Roussel, N. 2007. Flow and jamming of granular mixtures through obstacles. EPL (Europhysics Letters), 79(1), 14001.

Choi, C. E., Au-Yeung, S. C. H., NG, C. W. W., Song, D. 2015. Flume investigation of landslide granular debris and water runup mechanisms. Geotechnique Letters, 5, 28-32.

Choi, C.E., Liu, H, and Ng, C.W.W. 2017. Impact mechanisms of granular flow against curved barriers. Géotechnique Letters, 7(4): 330-338.

Christen, M., Bühler, Y., Bartelt, P., Leine, R., Glover, J., Schweizer, A., Graf, C., McArdell, B.W., Gerber, W., Deubelbeiss, Y., Feistl, T., Volkwein, A. 2012. Integral hazard management using a unified software environment: numerical simulation tool "RAMMS" for gravitational natural hazards. In: Koboltschnig, G., Hübl, J., Braun, J. (eds) 12th Congress INTERPRAEVENT, 23-26 April 2012 Grenoble - France. Proceedings. Vol. 1. Klagenfurt, International Research Society INTERPRAEVENT. 77-86.

Cui, P., Zeng, C., Lei, Y. 2015. Experimental analysis on the impact force of viscous debris flow. Earth Surface Processes and Landforms, 40(12), 1644-1655.

DeNatale, J.S., Iverson, R.M., and Major, J.J. 1999. Experimental testing of flexible barriers for containment of debris flows. USGS. Open-File Report 99-205.

Published by NRC Research Press 
DIN, EN-12385. 2009. Steel wire ropes. Beuth.

Egli, T. 2005. Objektschutz gegen gravitative Naturgefahren, Kantonale Gebäudeversicherung.

Faug, T., Caccamo, P., and Chanut, B. 2012. A scaling law for impact force of a granular avalanche flowing past a wall. Geophysical Research Letters 39(23): L23401.

Faug, T. 2015. Macroscopic force experienced by extended objects in granular flows over a very broad Froude-number range. European Physical Journal E 38(24): 110.

Hübl, J. and Holzinger, G. 2003. Kleinmassstäbliche Modellversuche zur Wirkung von Murbrechern, WLS Report 50 / Band 3, Universität für Bodenkultur, Wien.

Hübl, J., Suda, J., Proske, D., Kaitna, R., Scheidl, C. 2009. Debris Flow Impact Estimation. In: 11th International Symposium on Water Management and Hydraulic Engineering, Ohrid: WMHE; p.137148.

Hürlimann, M., Rickenmann, D., Graf, C. 2003. Field and monitoring data of debris-flow events in the Swiss Alps. Can. Geotech. J. 40: 161-175.

Iverson, R.M. 2015. Scaling and design of landslide and debris-flow experiments. Geomorphology. doi:10.1016/j.geomorph.2015.02.033.

Koo, R.C.H., Kwan, J.S.H., Ng, C.W.W., Lam, C., Choi, C.E., and Song, D. 2016. Velocity attenuation of debris flows and a new momentum-based load model for rigid barriers. Landslides, 14(2): 617629.

Koo, C. R., Kwan, S. J., Lam, C., Pun, W. K., Ng, W. C., Choi, E. C. 2017. Velocity Attenuation of Granular Debris Flows During Impact on Rigid Barriers. In Workshop on World Landslide Forum (pp. 385-390). Springer, Cham.

Kowalski, J. 2008. Two-phase modeling of debris flows. ETH Zurich.

Kwan, J.S.H. and Cheung R.W.M. 2012. Suggestions on Design Approaches for Flexible Debrisresisting Barriers, incl. Appendix C Comments and responses, Discussion Note DN 1/2012, GEO, Hong Kong.

Published by NRC Research Press 
Kwan, J.S.H., Chan, S.L., Cheuk, J.C.Y. and Koo, R.C.H. 2014. A case study on an open hillside landslide impacting on a flexible rockfall barrier at Jordan Valley, Hong Kong. Landslides, 11: 1037. doi:10.1007/s10346-013-0461-X.

Kwan, J.S.H., Koo, R.C.H., and Ng, C.W.W. 2015. Landslide mobility analysis for design of multiple debris-resisting barriers. Canadian Geotechnical Journal, 52(9): 1345-1359. 10.1139/cgj-2014-0152

Leonardi, A., Wittel, F. K., Mendoza, M., Vetter, R., Herrmann, H. J. 2016. Particlefluidstructure interaction for debris flow impact on flexible barriers. ComputerAided Civil and Infrastructure Engineering, 31(5), 323-333.

McArdell, B.W., Bartelt, P., and Kowalski, J. 2007. Field observations of basal forces and fluid pore pressure in a debris flow, Geophysical Research Letters, 34.

Ng, C.W.W., Song, D., Choi, C.E., Kwan, J.S.H., Shiu, H.Y.K., and Koo, R.C.H. 2016. Centrifuge modelling of dry granular and viscous impact on rigid and flexible barriers. Canadian Geotechnical Journal, (published online).

Ng, C.W.W., Song, D., Choi, C.E., Koo, C.H., and Kwan, J.S.H. 2016. A novel flexible barrier for landslide impact in centrifuge. Géotechnique Letters, 6(3), 221-225.

Ng, C.W.W., Choi, C.E., Koo, R.C.H., Kwan, J.S.H. 2017. Dry granular flow interaction with dualbarrier systems. Géotechnique, https ://doi.org/10.1680/jgeot.16.P.273.

NILIM. 2007. Manual of technical standard for establishing sabo master plan for debris flow and driftwood. Technical Note of NILIM No. 364. Natural Institute for Land and Infrastructure Management, Ministry of Land, Infrastructure and Transport, Japan. [In Japanese.]

Palkowski, S. 1990. Statik der Seilkonstruktionen, Springer Verlag.

Rankine, W. 1857. On the stability of loose earth. Philosophical Transactions of the Royal Society of London, Vol. 147, 9-27. doi:10.1098/rstl.1857.0003.

Rickenmann, D. 2001. Estimation of debris flow impact on flexible wire rope barriers, Internal technical report, Swiss Federal Research Insitute WSL, Birmensdorf, Switzerland.

Published by NRC Research Press 
Rickenmann, D., Hürlimann, M., Graf, C., Näf, D., and Weber, D. 2001. MurgangBeobachtungsstationen in der Schweiz. Wasser Energie Luft 93, 1/2: 1-8.

Rickenmann, D., Weber, D., Stepanov, B. 2003. Erosion by debris flows in field and laboratory experiments. In: Rickenmann, D., Chen, C.-I. (eds) Debris-Flow Hazards Mitigation. Mechanics, Prediction, and Assessment. Proc. of the third Int. Conf. on Debris-Flow Hazards Mitigation. Davos, Switzerland, September 10-12, 2003. Volume 2. Rotterdam, Millpress. 883-894.

Rickenmann, D., McArdell, B. 2007. Continuous measurement of sediment transport in the Erlenbach stream using piezoelectric bedload impact sensors. Earth Surf. Process. Landf. 32: 1362-1378.

Salm, B., Burkard, A., and Gubler, H. 1990. Berechnung von Fliesslawinen. Eine Anleitung für den Praktiker mit Beispielen, Tech. rep., Eidg. Institut für Schnee- und Lawinenforschung, SLF, Davos, Switzerland.

Savage, S.B., Hutter, K. 1989. The motion of a finite mass of a granular material down a rough incline. Journal of Fluid Mechanics, 199:177215.

Savage, S.B., Hutter, K. 1991. The dynamics of avalanches of granular materials from initiation to runout. part 1: Analysis. Acta Mechanica, 86:201223.

Schuerch, P., Densmore, A.L., McArdell, B., and Molnar, P. 2006. The influence of landsliding on sediment supply and channel change in a steep mountain catchment. Geomorphology 78: 222-235.

Song, D., Ng, C. W. W., Choi, C. E., Zhou, G. G., Kwan, J. S., Koo, R. C. H. 2017. Influence of debris flow solid fraction on rigid barrier impact. Canadian Geotechnical Journal, 54(10), 1421-1434.

Song, D., Choi, C. E., Ng, C. W. W., Zhou, G. G. D. 2018. Geophysical flows impacting a flexible barrier: effects of solid-fluid interaction. Landslides, 15(1), 99-110.

Volkwein, A. 2004. Numerische Simulation von flexiblen Steinschlagschutzsystemen, Ph.D. thesis, Swiss Federal Institute of Technology ETHZ, Zurich.

Volkwein, A. 2005. Numerical simulation of flexible rockfall protection systems. In: Proceedings of the International Conference on Computing in Civil Engineering, July 12-15, 2005, Cancun, Mexico. $11 \mathrm{p}$. 
Volkwein, A. 2014. Flexible debris flow barriers - Design and application. WSL Rep. 18: 29 pp.

Volkwein, A., Wendeler, C., Stieglitz, L., Lauber, G. 2015. New approach for flexible debris flow barriers. In: IABSE Conference Geneva, 2015 - Structural Engineering: Providing Solutions to Global Challenges. Report. September 23-25 2015, Geneva, Switzerland. Zürich, IABSE. 248-255.

Weber, D. 2004. Untersuchungen zum Fliess- und Erosionsverhalten granularer Murgänge, Dissertation, Eidgenössische Forschungsanstalt für Wald, Schnee und Landschaft WSL, Birmensdorf, http://e-collection. library.ethz.ch/view/eth:27330 (accessed 17 March 2016).

Wendeler, C. 2006. Video compilation of laboratory tests using different impact barriers, online visible on https://youtu.be/De3miIUdtlA

Wendeler, C. 2008. Murgangrückhalt in Wildbächen - Grundlagen zu Planung und Berechnung von flexiblen Barrieren, Ph.D. thesis, ETH Zurich (abstract in English).

Wendeler, C. 2016. Debris flow protection systems for mountain torrents - basic principles for planning and calculation of flexible barriers., WSL report, translation of $\mathrm{Ph} . \mathrm{D}$. thesis.

Wendeler, C., Volkwein, A., Roth, A., Nishimura, N. 2014. Successful hazard prevention using flexible multi-level barriers. Proc. Interpraevent.

Wendeler, C. and Volkwein, A. 2015. Laboratory tests for the optimization of mesh size for flexible debris-flow barriers, Nat. Hazards Earth Syst. Sci., 15, 2597-2604, doi:10.5194/nhess-15-25972015.

Zanuttigh, B., Lamberti, A. 2004. Analysis of debris wave development with one-dimensional shallowwater equations. Journal of Hydraulic Engineering, 130(4), 293-304. 